\title{
Alcohol-Mediated Organ Damages: Heart and Brain
}

\author{
Adam Obad ${ }^{\dagger}$, Ahmed Peeran ${ }^{\dagger}$, Janay I. Little, Georges E. Haddad and Sima T. Tarzami* \\ Department of Physiology and Biophysics, Howard University, Washington, DC, United States
}

\section{OPEN ACCESS}

Edited by:

Patrizia Ballerini,

Università degli Studi "g. D'annunzio"

Chieti - Pescara, Italy

Reviewed by:

Vishal Diwan

The University of Queensland,

Australia

Barbara Rossi,

University of Verona, Italy

*Correspondence:

Sima T. Tarzami

sima.tarzami@howard.edu

${ }^{\dagger}$ These authors have contributed equally to this work.

Specialty section: This article was submitted to Inflammation Pharmacology,

a section of the journal

Frontiers in Pharmacology

Received: 24 October 2017 Accepted: 24 January 2018

Published: 13 February 2018

Citation:

Obad A, Peeran A, Little Jl, Haddad GE and Tarzami ST (2018) Alcohol-Mediated Organ Damages:

Heart and Brain.

Front. Pharmacol. 9:81. doi: 10.3389/fphar.2018.00081
Alcohol is one of the most commonly abused substances in the United States. Chronic consumption of ethanol has been responsible for numerous chronic diseases and conditions globally. The underlying mechanism of liver injury has been studied in depth, however, far fewer studies have examined other organs especially the heart and the central nervous system (CNS). The authors conducted a narrative review on the relationship of alcohol with heart disease and dementia. With that in mind, a complex relationship between inflammation and cardiovascular disease and dementia has been long proposed but inflammatory biomarkers have gained more attention lately. In this review we examine some of the consequences of the altered cytokine regulation that occurs in alcoholics in organs other than the liver. The article reviews the potential role of inflammatory markers such as TNF- $\alpha$ in predicting dementia and/or cardiovascular disease. It was found that TNF- $\alpha$ could promote and accelerate local inflammation and damage through autocrine/paracrine mechanisms. Unraveling the mechanisms linking chronic alcohol consumption with proinflammatory cytokine production and subsequent inflammatory signaling pathways activation in the heart and CNS, is essential to improve our understanding of the disease and hopefully facilitate the development of new remedies.

Keywords: alcohol abuse, cytokines, TNF- $\alpha$, SDF-1, cardiovascular disease

\section{INTRODUCTION}

Alcohol is one of the most commonly abused substances in the United States. The effect of alcohol on organ systems of the body extends beyond the liver, where it is metabolized, to include the central nervous system, cardiovascular system, kidneys, lung, gastrointestinal tract, pancreas, and the immune system (Rodriguez et al., 2004; Walker et al., 2013). Due to its ability to distribute throughout most fluid compartments of the body (Dubowski, 1985), the chronic consumption of ethanol leads to cell injury in nearly every tissue, specifically cardiac tissue. Unfortunately, the incidence of heart disease due to chronic alcohol consumption continues to rise owing to the increased chronic alcohol drinking habits among American youth. In fact, individuals who abuse alcohol have been shown to have a high percentage of cardiovascular disease; the leading cause of death, disability, and healthcare expense in the United States.

Conventionally, liver injury due to alcohol consumption has been studied in depth. The liver is the main metabolizer of alcohol and hence alcohol has harmful effects on liver cells. The Long periods of alcohol abuse can cause the liver to become inflamed, swollen or scarred (cirrhosis; Louvet and Mathurin, 2015). However, recently there has been increasing momentum in studying alcohol-induced cardiac and CNS injury. Particularly, the relationship between inflammation and inflammatory markers with alcoholic heart disease has gained much attention lately. This review 
summarizes the recent progress on the deleterious effects of alcohol abuse on a person's general health with special focus on the heart and brain (Figure 1). These organs consist of permanent cells, where the mechanisms underlying ethanol mediated damage is still not clear. Understanding the nature of the deleterious effects of alcohol on these organs may provide new insights on how to manage and/or combat effectors of alcohol-induced cell injury.

\section{DELETERIOUS EFFECT OF CHRONIC EXCESSIVE ALCOHOL CONSUMPTION}

Generally speaking, mechanisms of alcohol-related organ injury were attributed to increases in oxidative stress, impairments in methylation, unusual posttranslational modifications of proteins, dysregulation in lipid metabolism and signal transduction pathways, all of which ultimately affect cell survival and function (Song et al., 2014). However, this review highlights the contribution of inflammatory processes in alcohol-mediated tissue damage specifically in the context of cardiac and CNS damage whose injury mechanisms are not yet fully understood. Postmortem studies of both human alcoholic brains and basic animal models have demonstrated that heavy alcohol use is associated with an increased incidence of myopathy and neuropathy suggesting heart and brain changes (Crews et al., 2004; Liu et al., 2004, 2006; Remick, 2013; Fernandez-Sola and
Planavila Porta, 2016). Interestingly heavy alcoholism is also associated with increased cytokine secretion and inflammation in these organs, reinforcing the possibility that cytokines play a pivotal role in alcohol-related brain and heart damages (Tables 1-2).

It is reported that alcohol abuse is associated with an increased incidence of a number of infectious diseases (Moss et al., 2003; Romeo et al., 2007). The effects of alcohol on the immune system involve various types of immune cells and their interactions. Using a murine model that parallels human alcoholism, Latif et al., has shown that alcohol impairs Th1-mediated delayed hypersensitivity (DTH) reactions (Wang et al., 2001; Latif et al., 2002). Furthermore, alcohol consumption in mice suppresses the cytolytic activity of natural killer (NK). Using mouse models, wherein mice were exposed to ethanol for relatively short periods of time (1-2 weeks), a significant reduction of splenic NK cells number was observed; this reduction directly correlated with a reduced NK cell activity in vitro (Meadows et al., 1992; Spitzer and Meadows, 1999). Spitzer and Meadows have shown that alcohol impairs the specific target-induced release, activity, and expression of cytolytic factors e.g., granular proteases and perforin, in fresh NK and IL2-stimulated NK in response to tumor targets (Meadows et al., 1992; Spitzer and Meadows, 1999). This ties into another aspect of alcoholic damage in which high doses of alcohol consumption can directly suppress a wide range of immune responses, causing increased susceptibility to certain diseases e.g., cancer (Lundberg and Passik, 1997).

Mechanisms of Alcohol Induced Tissue Injuries

Direct and Indirect Effects of Alcohol

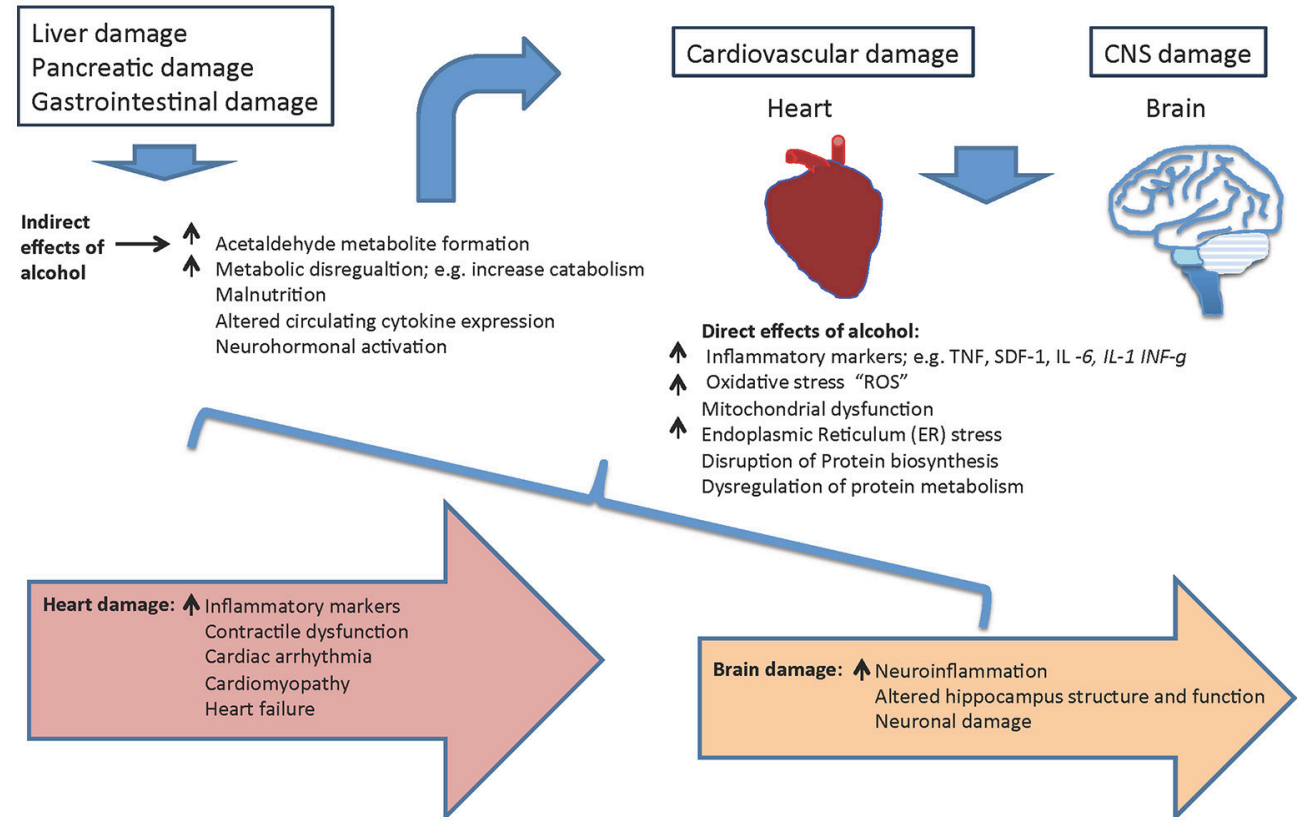

FIGURE 1 | Mechanisms of alcohol-induced tissue injuries. 
TABLE 1 | Neuroinflammation and associated cytokines.

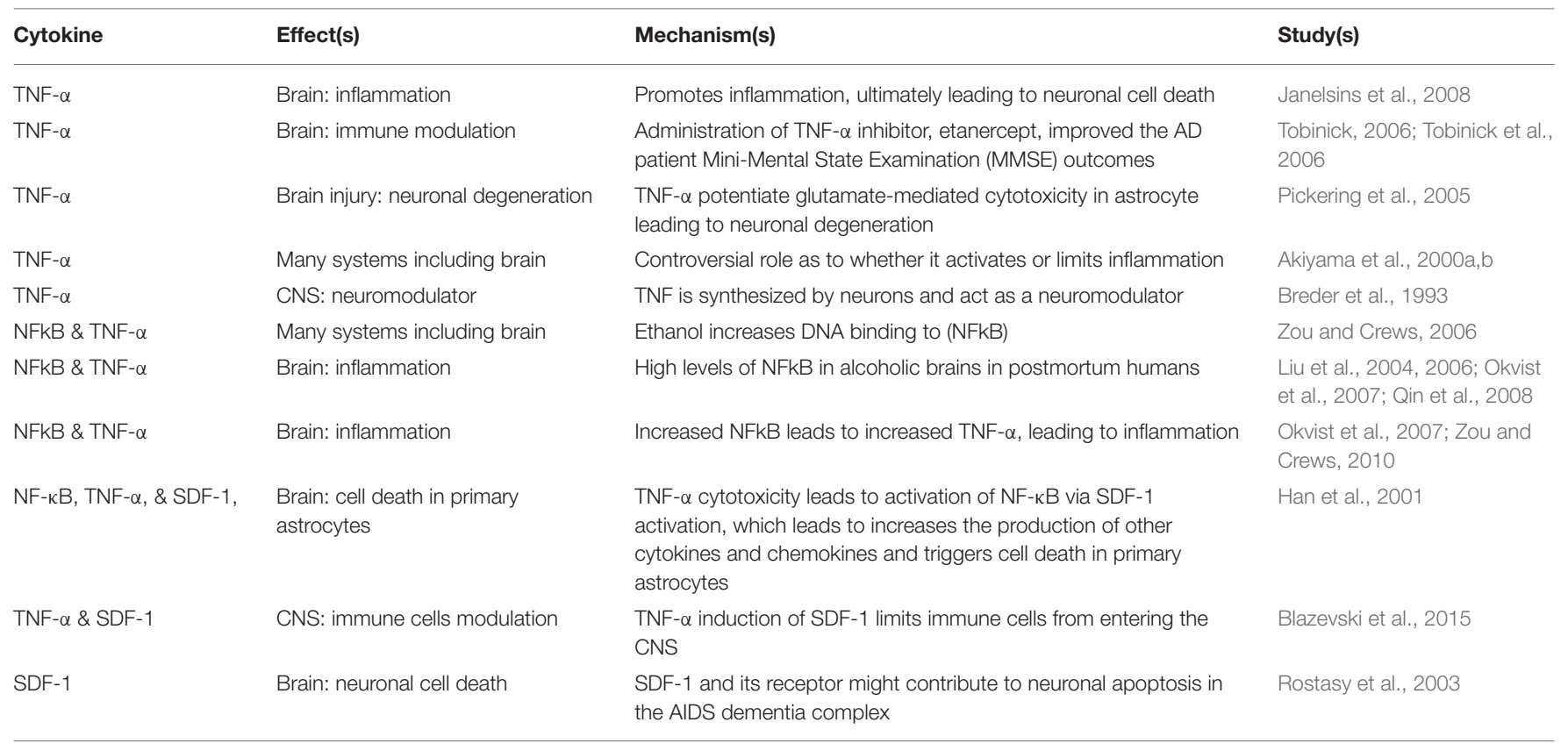

TABLE 2 | Potential mechanism(s) underlying alcohol-induced heart damages.

\begin{tabular}{|c|c|c|c|}
\hline Factor & Effect(s) & Mechanism(s) & Study \\
\hline Alcohol & $\begin{array}{l}\text { Reduction in contractility and ejection fraction, and } \\
\text { myopathies including hypertrophy and myofibrillal } \\
\text { abnormalities }\end{array}$ & Multifactorial & $\begin{array}{l}\text { Preedy et al., 2003; Kannan } \\
\text { et al., 2004; Li and Ren, 2008; } \\
\text { Umoh et al., } 2014\end{array}$ \\
\hline Alcohol & Stress on the heart & Circulatory changes & Ji, 2012 \\
\hline Alcohol & $\begin{array}{l}\text { Hypertrophy and increase the assembly of } \\
\text { sarcomeres }\end{array}$ & $\begin{array}{l}\text { Increased circulatory growth factors, cytokines, } \\
\text { and neurohormonal activation }\end{array}$ & $\begin{array}{l}\text { MacHackova et al., 2006; Ji, } \\
2012\end{array}$ \\
\hline Alcohol & $\begin{array}{l}\text { Alcoholic cardiomyopathy; agonist and time } \\
\text { dependent, activation with acute and deactivation } \\
\text { after chronic exposure }\end{array}$ & $\begin{array}{l}\text { Decrease the activation of the anti-apoptotic } \\
\text { pathway related to the Mitogen Activated Protein } \\
\text { kinases (MAPK) }\end{array}$ & $\begin{array}{l}\text { Aroor et al., 2002; Aroor and } \\
\text { Shukla, 2004; Li et al., } 2006\end{array}$ \\
\hline Alcohol & Alcoholic cardiomyopathy and heart failure & Cardiomyocyte apoptosis & Fernandez-Sola et al., 2006 \\
\hline $\begin{array}{l}\text { Heavy alcohol } \\
\text { consumption }\end{array}$ & $\begin{array}{l}\text { Ventricular arrhythmias and sudden cardiac death } \\
\text { (SCD) }\end{array}$ & Multifactorial & $\begin{array}{l}\text { Wannamethee and Shaper, } \\
\text { 1992; Leaf et al., } 2003\end{array}$ \\
\hline Heavy drinking & $\begin{array}{l}\text { Reduced ejection fraction and decreased } \\
\text { contractility; this effect is correlated with duration } \\
\text { and quantity of consumption }\end{array}$ & $\begin{array}{l}\text { Progressive disarrangement and fragmentation of } \\
\text { the myocytes' sarcomeres, defective pumping } \\
\text { machinery of the heart }\end{array}$ & $\begin{array}{l}\text { Danziger et al., 1991; Vary et al., } \\
2001\end{array}$ \\
\hline $\begin{array}{l}\text { In alcoholic } \\
\text { population }\end{array}$ & $\begin{array}{l}\text { Heart failure; reduction in stroke volume and low } \\
\text { ejection fraction }\end{array}$ & Multifactorial & $\begin{array}{l}\text { Patel et al., 1997a; } \\
\text { Urbano-Marquez and } \\
\text { Fernandez-Sola, 2004, } 2005\end{array}$ \\
\hline $\begin{array}{l}\text { Heavy alcohol } \\
\text { consumption }\end{array}$ & Alcohol-induced heart disease & Left ventricle dysfunction & $\begin{array}{l}\text { Haddad et al., 2008; Walker } \\
\text { et al., 2013; Umoh et al., } 2014\end{array}$ \\
\hline
\end{tabular}

Alcoholism's effects on the brain and heart vary and are influenced by a wide range of variables including the amount of alcohol consumed, the age at which the person began drinking, the duration of drinking, and several other factors
(Hommer, 2003; Zeigler et al., 2005; Haddad et al., 2008; Lemstra et al., 2008). Thus, this review is mainly devoted to analyzing the underlying mechanisms of damages associated with heavy alcoholism focusing on brain and heart. 


\section{CHRONIC EXCESSIVE ALCOHOL CONSUMPTION AND NEUROLOGIC DISORDERS}

It is well-documented that heavy alcohol consumption provokes an array of degenerative pathologies, but the effectors that couple alcohol exposure to regulated forms of cell death are poorly understood. Several factors determine the degree of alcohol effect on the brain including: the frequency at which a person drinks, the amount of consumption, the duration of drinking, family history of alcohol consumption, the prenatal alcohol exposure, genetic background, and the person's general health status (Estruch et al., 1993; Keenan et al., 1997; Cervilla et al., 2000; Baumgartner et al., 2002; Oscar-Berman and Bowirrat, 2005). Not only does excessive alcohol consumption causes a person to be intoxicated, but it also increases his/her risk of experiencing blackouts. Blackouts are "intervals of time for which the intoxicated person cannot recall key details of events, or even entire events" (Hartzler and Fromme, 2003; Kahkonen et al., 2003).

Brain shrinkage is a common sign of brain damage; studies have shown that alcoholic men and women have significant shrinkage of their brains compared to non-alcoholic subjects. Similarly alcohol consumption causes impairment in their memory as well as their learning abilities (Wilkinson and Carlen, 1980; Eckardt et al., 1998; Nolen-Hoeksema and Hilt, 2006). Interestingly, in these studies women have shown higher susceptibility to these health problems, therefore they are more vulnerable. Unfortunately, these studies comparing men and women have been inconclusive.

Besides the overall effect on the brain, alcoholism can be detrimental to the cerebellum. Harm to the cerebellum mainly leads to loss of muscular coordination. The staggering gait and associated imbalance is a manifestation of the muscular coordination loss due to cerebellar damage (Oscar-Berman and Pulaski, 1997). The effect of alcohol could extend to the peripheral nervous system leading to peripheral neuropathy reflected as numbness and weakness in the hands and feet.

Korsakoff's syndrome (KS) is another recognizable complication of chronic excessive alcohol consumption (Oscar-Berman and Pulaski, 1997). In this syndrome, patient has memory loss with difficulty remembering their daily activities shortly after their occurrence, for which they are stuck in their old memories. The clinical manifestation of this syndrome is believed to be influenced by the genetic makeup of alcoholics, who might be predisposed to developing several forms of amnesia. Furthermore, some of these patients cannot properly process thiamine or vitamin B efficiently due to an enzyme deficiency (Oscar-Berman and Pulaski, 1997). The high alcohol consumption and low utility of thiamine can lead to brain damage, which causes the amnesia. Although these alcoholic patients experience amnesia, this does not directly affect their long-term memory, which includes their intelligence, as well as memories formed before the development of the disease (Oscar-Berman and Pulaski, 1997; Nixon, 2006).

There is strong evidence supporting the fact that alcohol exposure during developmental stages results in devastating selective neuronal damage resulting in profound central nervous system (CNS) deficits. The severity of this damage depends on the duration, and frequency of exposure to ethanol during gestation. There is strong evidence that during prenatal development alcohol exposure has negative consequences, however, the causes ethanol-induced neurodegeneration are poorly understood. Alcohol has been linked to hyper-inflammation, reactive oxygen species (ROS) generation and ultimately neuronal death (Ke et al., 2011; Fernandez-Lizarbe et al., 2013). Recent evidence appears to support an involvement of ER stress in alcoholinduced neuron toxicity. Increase of ER stress response proteins, i.e., ATF6, CHOP, GRP78, and mesencephalic astrocyte-derived neurotrophic factor as well as the phosphorylation of IRE1, eIF2 $\alpha$, PERK, and PKR were also detected within $24 \mathrm{~h}$ after the ethanol exposure (Bommiasamy et al., 2009; Ke et al., 2011). It has also been suggested that alcohol triggers an inflammatory response and causes a hyper-inflammation status, which mediates its damaging effects. Fernandez-Lizarbe et al. (2013), demonstrated that in microglial cells ethanol up-regulates TLR4 and TLR2 recruitment into lipid rafts-caveolae, mimicking their activation by their ligands (Fernandez-Lizarbe et al., 2013). This in turn will trigger induction of inflammatory mediators, generation of ROS and ultimately leads to neuroinflammation and neuronal cell death.

Chronic alcohol abuse also affects the integrity of blood-brain barrier (BBB), which can increase the influx of proinflammatory mediators and leukocytes into the brain. The BBB consists of the mainly of specialized endothelial cells lining the cerebral blood vessels, surrounded by pericytes, astrocytical processes, and neurons. It is known that alcohol can directly pass through the $\mathrm{BBB}$, ultimately reaching the brain cells and causing subsequent neuronal toxicity, however the underlying mechanism is not fully understood. It was indeed suggested that chronic ethanol exposure induces oxidative stress and neuroinflammation in part by affecting platelet endothelial cell adhesion molecule-1 (PECAM-1) expression.

Endothelial PECAM-1 is a cell adhesion molecule that allows for the interaction of immune cells and the endothelium which facilitates the transmigration of leukocytes and thus contributes to the endothelial cell permeability barrier (Lertkiatmongkol et al., 2016); endothelial PECAM-1 (not Leukocytic PECAM1 ) is the key regulatory component in this process (Wong and Dorovini-Zis, 1996; Lertkiatmongkol et al., 2016; Mandyam et al., 2017). It was reported that PECAM-1 may contribute to $\mathrm{BBB}$ damage, decline in oligodendrogenesis, demyelination and subsequent cognitive dysfunction (Mandyam et al., 2017). More over PECAM-1 could enhance the expression of NF$\mathrm{kB}$, a proinflammatory transcription factor which is produced under conditions of oxidative stress. Upregulation of NF-kB signaling further enhances the immune response, and this, in conjunction with impaired vascular endothelial integrity, could further facilitate the infiltration of leukocytes into the brain (Mandyam et al., 2017).

A review of the literature demonstrates that PECAM plays multiple pro-inflammatory roles in the current clinical context; however, there is evidence to suggest that there are also antiinflammatory mechanisms regulated by endothelial PECAM-1. 
PECAM-1 was found to increase the resilience of the endothelial cell barrier and to suppress the proinflammatory cytokines which in turn dampened leukocyte infiltration into the brain (Privratsky et al., 2010). Although, the mechanisms through which PECAM1 regulates these opposing functions is not fully understood, it is clear that PECAM-1 plays an important role in maintaining $\mathrm{BBB}$ integrity and may contribute to pathological inflammatory phenotype seen in alcoholism.

\section{NEUROINFLAMMATION AND CYTOKINE LEVELS}

The importance of pro-inflammatory cytokines has been implicated in neuroinflammation, neuroprotection, and neurogenesis (Choi et al., 2008). Of all cytokines the most widely investigated pro-inflammatory cytokines are Interleukin-1 $\beta$ (IL-1 $\beta$ ), interleukin-6 (IL-6), Interferon-gamma (IF- $\gamma$ ) and tumor necrosis factor- $\alpha$ (TNF- $\alpha$; Munoz-Fernandez and Fresno, 1998; Bauer et al., 2009). Unlike physiological conditions where cytokines' levels are kept at low levels, pathological conditions can increase their levels up to 100-folds the normal levels (Pitossi et al., 1997; Lee et al., 2002). For example, during trauma or injury to the nervous system, glial cells are shown to be activated, which leads to the production of a plethora of cytokines (Munoz-Fernandez and Fresno, 1998; Sheng et al., 2011). An important role of cytokines pertaining to their pro-inflammatory effect is their ability to upregulate cell adhesion molecules leading to alteration of the $\mathrm{BBB}$ integrity.

Among the inflammatory mediators, special interest has been paid to TNF- $\alpha$. In addition to its key proinflammatory role, this pleiotropic cytokine mediates several pathological and physiological processes such as inflammation, differentiation, and apoptosis (Table 1; Janelsins et al., 2008). Referred to as the "master regulator," TNF- $\alpha$ initiates and modulates the immune response in many systems including the brain (Tobinick, 2006; Tobinick et al., 2006). TNF- $\alpha$ role in normal brain functions has not been fully understood. Yet, many postulated hypotheses about many important CNS-related functions; an example of which, is its role in the development of hippocampal neurons (McCoy and Tansey, 2008). TNF- $\alpha$ levels elevation was implicated in ischemic and traumatic brain injuries (Pickering et al., 2005). Furthermore, TNF- $\alpha$ has an essential role in starting and regulating the steps of cascades of several cytokines during inflammation (Tobinick et al., 2006; Blazevski et al., 2015). However, the exact physiological role of TNF- $\alpha$ posed a challenge to scientists due to its low levels in healthy brains. The source of TNF- $\alpha$ and other inflammatory cytokines and neurotoxic substances during inflammation have been suggested to be by activated microglial cells (Breder et al., 1993). During the neuroinflammatory status in many neurological disorders, microglial cells release a plethora of newly synthesized TNF- $\alpha$. However, the role of TNF- $\alpha$ remains controversial as to whether it exacerbates the neuronal injury or actively limits injury (Akiyama et al., 2000a,b). Hence, some clinical and preclinical studies postulated that interfering with TNF- $\alpha$ action in the brain might reduce the severity and delay the progression of many neurodegenerative disorders (McCoy and Tansey, 2008).

In Alzheimer's disease (AD), not only is there abnormal production of TNF- $\alpha$, but TNF- $\alpha$ has also been linked to the pathological neuromodulation of the disease (McAlpine et al., 2009; Swardfager et al., 2010). Significantly elevated levels of TNF- $\alpha$ were associated with early onset AD; with 65 years of age as the cut of point between early and late onset AD (GezenAk et al., 2013). When serum levels of TNF- $\alpha$ were compared between patients who have severe or mild forms of $\mathrm{AD}$, higher levels of TNF- $\alpha$ seems to correlate with increased severity and faster rate of the disease progression (McCoy and Tansey, 2008).

Alcohol is well-known for its dysregulation of cytokines levels in several body organs such as the liver, brain, lung, and plasma. It has been postulated that such changes are responsible for undesirables CNS alterations, which results in long term effects in behavior and permanent neurodegenerative effect. Hence, understanding the role of such cytokines is essential to determine the exact pathogenesis of alcohol-associated neurological disorders (Achur et al., 2010). The aforementioned dysregulation of cytokines production was also found to be abnormal during monocytes response to several pathogens as well. The exact mechanism of alcoholic disruption of cytokines production and inflammation is not fully understood, yet, many pathways were suggested to contribute to the pathogenesis of alcoholic diseases (Manzo-Avalos and Saavedra-Molina, 2010; Crews et al., 2015).

Along with other cytokines, TNF- $\alpha$ was found to be dysregulated by alcohol-related tissue destruction as is evident by the abnormal levels of circulating cytokines in alcoholic patients (Achur et al., 2010). It was shown that ethanol treatment increases DNA binding to NFkB transcription factor (Zou and Crews, 2006). NFkB activation is proinflammatory and leads to increases in the transcription of TNF- $\alpha$ production, it has also shown to be associated with ethanol-induced inflammation (Okvist et al., 2007; Zou and Crews, 2010). Furthermore, postmortem studies of human alcoholic brain shows higher expression of $\mathrm{NFkB}$ transcription and related proinflammatory genes in the brains of alcoholics suggesting a likely link between the neuroinflammation and alcohol-induced neurodegeneration (Liu et al., 2004, 2006), similar results were also found in animal studies which have associated alcohol intake to proinflammatory gene expression and brain neuronal cell death (Okvist et al., 2007; Qin et al., 2008).

\section{CHRONIC EXCESSIVE ALCOHOL CONSUMPTION AND HEART DAMAGES}

Alcohol can be beneficial or harmful and may affect the heart and whole cardiovascular system in many ways. Some of the cardiovascular diseases that are associated with heavy drinking are: cardiomyopathy, cardiac arrhythmias, hypertension, atherosclerosis and heart failure (Table 3; Hansson et al., 2002; Steinbigler et al., 2003; Guo et al., 2012; Da Silva et al., 2013). In this section we are mainly focusing on cardiac abnormalities that are associated with heavy alcohol consumption. There 
TABLE 3 | Potential mechanisms underlying alcohol consumption and cardiovascular disease.

\begin{tabular}{|c|c|c|}
\hline Cardiovascular disease & Potential mechanism(s) & Studies \\
\hline Hypertension & Increase in catecholamine secretion & Da Silva et al., 2013 \\
\hline Atrial fibrillation & Increase in reactive oxidative metabolites. & Steinbigler et al., 2003 \\
\hline Atherosclerosis & $\begin{array}{l}\text { Activation of innate and adaptive immunity, Presence of inflammatory } \\
\text { mediators e.g., TNF and IFN-gamma }\end{array}$ & Hansson et al., 2002 \\
\hline Alcoholic cardiomyopathy & $\begin{array}{l}\text { Increase in pro-inflammatory effect, neurohormonal activation, Metabolic } \\
\text { changes, acetaldehyde accumulation, impaired protein synthesis }\end{array}$ & MacHackova et al., 2006; Guo et al., 2012; Ji, 2012 \\
\hline Heart failure & $\begin{array}{l}\text { Cardiovascular disease, coronary artery disease, malnutrition, vitamin } \\
\text { deficiency }\end{array}$ & $\begin{array}{l}\text { Faris et al., 2003; Urbano-Marquez and Fernandez-Sola, } \\
\text { 2004, 2005; Fernandez-Sola et al., } 2006\end{array}$ \\
\hline
\end{tabular}

is sufficient documentation supporting the fact that excessive chronic consumption of alcohol increases the risk to develop several cardiovascular pathologies such as: reduction in contractility and ejection fraction, and myopathies including hypertrophy and myofibrillal abnormalities (Table 2; Preedy et al., 2003; Kannan et al., 2004; Li and Ren, 2008; Umoh et al., 2014). Alcohol may change the circulatory hemodynamics resulting in stress on the heart (Ji, 2012). The stressed myocytes undergo hypertrophy and increases the assembly of sarcomeres in response to the high demand of cardiac output; such effect is likely caused by increased circulating growth factors and cytokine along with neurohormonal activation (Table 2; MacHackova et al., 2006; Ji, 2012). Furthermore, alcohol-induced heart disease is believed to result from the left ventricle dysfunction that results from heavy chronic alcohol drinking habits (Table 2; Haddad et al., 2008). Many of these cardiovascular diseases associated with alcohol abuse can eventually develop to heart failure and unfortunately; this becomes a major public health issue and a burden on the health system (Djousse and Gaziano, 2008a,b; Haddad et al., 2008).

According to Djousse and Gaziano, approximately half a million Americans are diagnosed with heart failure each year and some of those cases are associated with alcohol consumption (Djousse and Gaziano, 2008b). Additionally, the effect of chronic alcohol intake on cardiomyocytes was correlated with the dose of consumption (Table 2; Haddad et al., 2008; Umoh et al., 2014). As opposed to heavy drinking, which was proven to increase the risk to develop cardiac failure, chronic low or moderate consumption was associated with lower risk of developing heart failure (Kagan et al., 1989; Wannamethee and Shaper, 1992; Wannamethee et al., 1995; Albert et al., 1999). The defining cut point between heavy and light-to-moderate consumption is different between men and women; being 1 cup per day for the latter and 2 cups per day for the earlier (Djousse and Gaziano, 2008b). Unfortunately, not many studies were dedicated to reveal the exact risk of developing heart failure in relation to specific types of alcoholic beverages (Djousse et al., 2004a). A link between the incidence of ventricular arrhythmias and sudden cardiac death (SCD) and heavy drinking has been suggested (Wannamethee and Shaper, 1992; Leaf et al., 2003). In patients with history of excessive drinking for 5-10 years, alcohol-related myocytes disease was associated with left ventricle changes such as dilation, increased mass, and normal or reduced thickness of the wall (Adams and Hirst, 1990; Chen et al., 2000; Jankala et al., 2001; Vary and
Deiter, 2005). However, current literature does not have sufficient data to determine the duration and quantity required to manifest the frank picture of alcoholic cardiomyopathy. However, many retrospective studies found a minimum history of 10 years of excessive consumption among symptomatic alcoholic heart failure patients. Abstinence from drinking in such patients may reduce further risk and improve survival (Nicolas et al., 2002).

Cardiac disease remains an essential burden that causes death in chronic alcoholic population (Kannel, 1998; Banks, 2008). Excessive and prolonged alcohol drinking can lead to cardiovascular injuries known as alcoholic heart muscle disease leading to reduced ejection fraction and decreased contractility; a syndrome that is not usually caused by shortterm consumption (Danziger et al., 1991; Vary et al., 2001). Correlating with the quantity and duration of drinking, the progressive disarrangement, functional loss, and fragmentation of the myocytes' sarcomeres seems to interfere with pumping machinery of the heart and reduces its performance (Vary et al., 2001). However, causal relationship between heaving drinking and alcoholic heart disease remains equivocal and debatable (Richardson et al., 1986). Unlike with liver disease, no studies have determined the relation between the quantity of consumption and alcoholic cardiomyopathy, rather it is a clinical diagnosis in heavy drinkers who have no other obvious causes for their heart disease (Richardson et al., 1986).

Despite the lack of clear understanding of the exact mechanism by which chronic alcohol consumption causes heart failure, stroke volume reduction and low ejections fraction was found in alcoholic population (Patel et al., 1997a,b; UrbanoMarquez and Fernandez-Sola, 2004, 2005). Such effect was found to be related to the dose of alcohol, regardless of the presence or absence of coronary artery disease, malnutrition, and/or vitamin deficiencies (Faris et al., 2003; Urbano-Marquez and FernandezSola, 2004; Fernandez-Sola et al., 2006). Hence, alcoholic cardiomyopathy occurs in chronic alcohol heavy drinkers, who do not manifest any other cause for their underlying pathology (Wodak and Richardson, 1982; Richardson et al., 1986).

\section{ALCOHOL AND CARDIOMYOCYTE APOPTOSIS/SURVIVAL}

Recent evidence shows that cardiomyocyte apoptosis appears to play a major role in many alcoholic cardiomyopathies leading to heart failure (Fernandez-Sola et al., 2006). Specifically, alcohol 
seems to decrease the activation of a very important survival pathway, Akt (Aroor et al., 2002), as well as that of the antiapoptotic pathway related to the Mitogen Activated Protein kinases (MAPK), in cardiac myocytes (Table 2; Zhang et al., 2003; Aroor and Shukla, 2004; Li et al., 2006). Such effects have been shown to be agonistic and time dependent, showing an early activation with acute exposure, shifting into deactivation after chronic exposure (Table 2; Li et al., 2006). This is consistent with the J-shaped inverse association between alcohol and cardiovascular disease morbidity and mortality (Panagiotakos et al., 2001; Sempos et al., 2003; Aistrup et al., 2006). Furthermore, acute exposure to high-doses of ethanol treatment induces cardiomycyte apoptosis in a concentration-dependent manner (Altura et al., 1996). High alcohol consumption is associated with myocyte metabolic changes such as decrease in respiratory enzyme and lactate dehydrogenase activity, a decrease in beta oxidation of fatty acids, increase in alcohol dehydrogenase activity which may lead to acetaldehyde accumulation and impaired protein synthesis eventually leading to myocardial injury (Guo et al., 2012).

Sparagna et al. has shown that low-dose alcohol attenuates apoptosis in neonatal rat cardiocytes through Akt and AMPactivated kinase (Sparagna et al., 2004). Converging data are implicating the weakening of the insulin-like growth factor1 (IGF-1)/PI3 Kinase pathway as an important mechanism of alcohol induced injury (Table 2; Chen et al., 2000). Work from others and our laboratories have shown that the survival benefits of IGF-1 are mainly mediated through PI-3K and to a lesser extent through the MAPK (Teos et al., 2008; Umoh et al., 2014). We have previously shown that PI-3K-dependent IGF-1 signaling activates downstream mTOR pathway in cardiac hypertrophy (Bamji and Haddad, 2015). In addition, IGF-1 receptors and IGF1 mRNA levels were not affected by chronic alcohol treatment of rats (Pecherskaya et al., 2002). However, there was a higher basal level of IGF-1 receptor activation in alcoholic cardiac protein preparations. Works from other laboratories indicates a negative regulation of $\mathrm{I}_{\mathrm{K}}$, by IGF-1 mainly through PI-3K/Akt activation (Teos et al., 2008). This may imply that the alcoholinduced depression in $I_{K}$ reported earlier maybe mediated by IGF-1-dependent signaling pathway.

\section{LOW-DOSE ALCOHOL BENEFICIAL CARDIOVASCULAR EFFECTS}

Even though long-term alcohol abuse has been associated with defect in cardiac contractility and eventual development of dilated cardiomyopathy and low-output heart failure (Table 2; Preedy et al., 2003), interestingly however, low alcohol consumption has been associated with reducing risk of heart disease and stroke (Berger et al., 1999; Djousse et al., 2004b). Although several hypotheses have been postulated for alcoholic cardiomyopathy and for the low-dose beneficial cardiovascular effects, the precise mechanisms and mediators remain largely undefined. There is a remarkable lack of data in the literature regarding the electrophysiological alterations associated with different levels and length of alcohol exposure in cardiomycytes.
Most of the experimental evidence indirectly relates chronic alcohol-dependent changes in intracellular $\mathrm{Ca}^{2+}\left(\mathrm{Ca}_{\mathrm{i}}^{2+}\right)$ to contraction dysfunction without assessing the density and/or activity of neither the $\mathrm{Ca}^{2+}$ channels nor their inactivation parameters. Interestingly, no data is available on the electrophysiological effects of low alcohol exposure or on the exposure frequency. Clinically relevant concentrations of ethanol induced elevation of $\mathrm{Ca}_{\mathrm{i}}^{2+}$ that was dependent on voltage-gated entry into the myocytes through $\mathrm{I}_{\mathrm{Ca}, \mathrm{L}}$ (Brown et al., 1996; Solem et al., 2000) and reduction in the amplitude of $\mathrm{K}^{+}$ currents of rats (Nakamura et al., 1999; Dopico, 2003; Liu et al., 2003). It was shown that the density of dihydropyridine binding sites were greater in cardiomycytes isolated from ethanolconsuming rats as compared to control groups (Brown et al., 1996). On the other hand, acute exposure to ethanol has been shown to depress cell shortening and $\mathrm{Ca}^{2+} \mathrm{i}$ in a concentration dependent manner (Ren, 2007). Interestingly, acute exposure to low dose of ethanol reduced the contraction amplitude of the adult rat cardiomycytes; while such effect was associated with lower $\mathrm{Ca}_{\mathrm{i}}^{2+}$ when exposed to high doses. Moreover, the beneficial effect of low-dose alcohol was also attributed in part to the fact that ethanol is metabolized differently at low and high concentrations. It was suggested that low ethanol intake has the ability to increase antioxidant capacity, however, at high concentrations ethanol is metabolized to acetaldehyde without producing reduced nicotinamide adenine dinucleotide $(\mathrm{NADH})$. Instead, this pathway utilizes reduced nicotinamide adenine dinucleotide phosphate (NADPH), another reducing equivalent, thus producing an oxidative environment (Lieber, 1990). Interestingly, several studies reported beneficial effects with supplementation of antioxidants in people with essential hypertension and atherosclerotic endpoints (Rimm et al., 1993; Stephens et al., 1996).

\section{RELATIONSHIP BETWEEN INFLAMMATORY MARKERS AND ALCOHOLIC HEART DISEASE}

Although once thought of as part of inflammatory cells only, cytokines and chemokines are now recognized to play pivotal role in cardiac homeostasis and repair (Tarzami et al., 2002, 2003, 2005; Jougasaki, 2010; LaRocca et al., 2010). Ever since, studies postulated the important role of cytokines in cardiovascular diseases (Ferrari, 1999). It has been found that cytokines are continuously produced, however, they are upregulated in oxidative stress status of the heart. Furthermore, the level of circulating cytokines was inversely associated with left ventricular function (Aukrust et al., 1998). For example, Interleukin- 8 was one of the first chemokines to be related to myocardial injury ( $\mathrm{Oz}$ et al., 1995; Husebye et al., 2014). Similarly, Chemokines (c-c motif) Ligand2 (CCL2) and CCL5 are tremendously involved in heart failure and the death of injured myocardial cells, respectively (Braunersreuther et al., 2010; Abe et al., 2014). Nevertheless, the exact role different cytokines in cardiac pathology remains a largely disputable issue among scientists. 
The relationship between inflammation and inflammatory markers with alcoholic heart disease has gained much attention lately. In an in vivo study on pregnant Wistar Rats, the authors extrapolated that the inflammation and oxidative stress are the mechanisms of the destructive effect of ethanol on their hearts (Shirpoor et al., 2015). Furthermore, association studies have undoubtedly affirmed the presence of fluctuating levels of inflammatory markers in alcoholic heart disease. For example, IL- $6,-8,-12$, TNF- $\alpha$ and its receptors-TNF-R were high in patients with alcoholic cardiomyopathy; the higher the severity of the cardiomyopathy the higher the level of these markers (Panchenko et al., 2015). Moiseev and colleagues found the same results in patients with congestive heart failure who had a previous history of alcohol-induced cardiac damage compared to patients who have ischemic cardiomyopathy (Moiseev et al., 2013).

Among these inflammatory markers, TNF- $\alpha$ was particularly interesting for its role in cardiovascular diseases (Ferrari, 1999). In addition to its proinflammatory effect, TNF $\alpha$ has a negative inotropic action on cardiomyocytes (Torre-Amione et al., 1996). In addition to mast cells, which are a notable source of $\mathrm{TNF} \alpha$, the heart is a TNF-producing organ (Gordon et al., 1990; Meldrum et al., 1998). Unlike during physiological conditions, where TNF $\alpha$ levels are low, during heart failure both myocardial macrophages and cardiomyocytes produce a plethora of TNF $\alpha$; during congestive heart failure, for example, TNF- $\alpha$ were found to be elevated in advanced stages (Meldrum et al., 1998; TorreAmione et al., 1999; Feldman et al., 2000). Such an effect of TNF- $\alpha$ was consistent with the previous findings on the role of TNF- $\alpha$ in modulating peripheral resistance and the contractility of cardiomyocytes; two core factors that control hemodynamics of the heart function and the circulation (Ferrari, 1999).

The locally produced autocrine TNF- $\alpha$ was found to have a noticeable role in alcohol-related heart failure (Meldrum et al., 1998). As a matter of fact, it was postulated that high level of TNF- $\alpha$ could cause severe cardiac pathologies and participate in changes such as remodeling, fibrosis, and apoptosis (Bryant et al., 1998). Nonetheless, it remains controversial whether TNF- $\alpha$ causes favorable or detrimental effects on the cardiovascular system (Cacciapaglia et al., 2014).

\section{THERAPEUTIC APPROACHES TO IMPROVE ALCOHOL-INFLICTED ORGAN DAMAGES}

Alcoholism is a multifactorial disorder that requires a multidisciplinary approach to treat depending on the organs affected. Heavy drinkers suffer from many organ damages; among the most effected organs are liver and kidney. As we mentioned before, heart and brain can be affected either directly or indirectly by alcohol and or its breakdown metabolites. So far, conventional treatment strategies have used a combination of a reduction of ethanol-dependent inflicted damage by control drinking and increasing local and systemic protective mechanisms of the body by using antioxidant supplementation (Mailloux, 2016). In the cases of alcohol induced cardiovascular damage the use of anti-inflammatory (Doe et al., 2007; Panchenko et al., 2015), anti-fibrotic and anti-apoptotic (Yang et al., 2013) agents was also suggested.

Other non-conventional suggested approaches included the use of microRNAs since they are shown to play an important role in multi-organ alcohol-induced damages including brain and heart (Natarajan et al., 2015). Altered expression of circulation microRNAs in response to alcoholism has been reported, it was suggested that circulating microRNAs could serve as biomarker and prognostic marker for alcoholism and the degree of damages (Chen Y. J. et al., 2013; Chen Y. P. et al., 2013; Roderburg and Luedde, 2014; Jing et al., 2015). Altered expressions of microRNAs were noted in patients with alcoholic cardiomyopathy and/or brain injury (Jing et al., 2015). The importance of alcohol induced-microRNAs in regulating proinflammatory cytokine e.g., TNF- $\alpha$ and subsequent activation of immune-mediated reaction were also reported (Willeit et al., 2013). miR-155 expression is induced by alcohol and causes activation of NFkB and subsequent increase in TNF- $\alpha$ production in kupffer cells and macrophages, treatment with anti-sense-miR155 prevented the TNF- $\alpha$ production. Interestingly, ethanolinduced increase in TNF- $\alpha$ expression in the brain was due to an increase in the expression of miR-155. Mice deficient in miR155 did not show any increase in proinflammatory cytokine levels (e.g., TNF- $\alpha$ ) in the brain following ethanol exposure. This suggests an association between certain microRNAs and proinflammatory cytokine (e.g., TNF- $\alpha$ ), in ethanol consumption induced neuroinflammation and subsequent brain injury (Lippai et al., 2013).

\section{ROLE OF TNF- $\alpha$ IN ALCOHOL-INDUCED HEART DAMAGE}

Alcohol consumption effects cardiovascular system and predisposes to the development of cardiac abnormalities such as cardiac remodeling, cardiac arrhythmia, cardiomyopathy myocardia infarction, and even SCD (Table 3; Djousse and Gaziano, 2008b; Lai et al., 2011; Xiao et al., 2014; Guzzo-Merello et al., 2015). Consequently, many of these cardiac abnormalities will predispose the patients to development of heart failure thus treatment of alcohol induced heart damages is in accordance with the current clinical treatment of their specific heart condition. Since TNF- $\alpha$ was found to have a noticeable role in alcoholrelated heart failure (Meldrum et al., 1998), we are interested in the role of cytokines in particular TNF- $\alpha$ in development and progression of heart failure.

Heavy drinking has been shown to increase the risk of heart failure, thus in addition to the conventional approach to control alcoholism, it is critical to focus on preventive measures that could reduce the risk to heart failure in these patients. It was reported that normal heart does not express TNF but failing heart procures robust amount of TNF- $\alpha$, Hence, more studies are dedicated to understanding the role of TNF- $\alpha$ in heart failure patients. It is known that TNF- $\alpha$ is elevated in chronic heart failure patient in accordance with their functional class (Heberto Herrera Garza et al., 2002). Such an increase was found to 
have a linear correlation with the prognosis of chronic heart failure patients (Heberto Herrera Garza et al., 2002). Notably, a concordant reduction in TNF- $\alpha$ receptors on the cardiac myocytes was noticed in heart failure patients too, which was attributed to the high circulating levels of TNF- $\alpha$. Studies on animal models have shown the harmful effect of the negative inotropic effect of TNF- $\alpha$ on heart failure patients, in whom no transplant was performed (Heberto Herrera Garza et al., 2002). These findings are consistent with changes in TNF- $\alpha$ after improvement of pressure and volume overload, which results from hypertrophic obstructive cardiomyopathy (HOCM) and terminal dilated cardiomyopathy, using ethanol ablation and ventricular assistance, respectively (Heberto Herrera Garza et al., 2002).

Attempts to integrate TNF- $\alpha$ antagonist into the realms of therapeutic medicine has been suggested, with possible effectiveness for symptomatic heart failure patients (Heberto Herrera Garza et al., 2002). Tumor Necrosis Factor Receptor 1 (TNFR1) and TNFR2 are two cell surface receptors for TNF- $\alpha$, through which it achieves its various outcomes. Yet, variation in expression of these receptors and its regulation during cardiac disease status is not known.

Interestingly, in brain injury, TNF- $\alpha$ has been postulated to potentiate glutamate-mediated cytotoxicity in astrocyte leading to neuronal degeneration (Pickering et al., 2005). Han et al. (2001), have contributed some of the TNF- $\alpha$ cytotoxicity to TNFmediated stromal-derived factor-1 (SDF-1) activation of NF$\kappa \mathrm{B}$, during which it increases the production of other cytokines and chemokines and triggers cell death in primary astrocytes (Table 1; Han et al., 2001). Several studies have also linked the expression of TNF- $\alpha$ or SDF-1 to many cardiac pathological conditions, however, a link between TNF- $\alpha$, SDF-1 and their association with severity of alcohol mediated cardiac disease has not been explored.

SDF-1, otherwise known as CXCL12, plays a major role in regulating stem cell recruitments, inflammation and inflammation mediated injury (Doring et al., 2014; Wang et al., 2014). These roles are made possible mainly through the interactions of SDF-1 and its receptors CXCR4 and CXCR7, with CXCR4 being suggested as the primary receptor due to the fact that selective CXCR4 receptor antagonists block many effects of SDF-1 (Wei et al., 2014). The production of SDF-1 is stimulated by various pro inflammatory stimuli such as TNF- $\alpha$ (Feng et al., 2014). Moreover, TNF- $\alpha$ has been shown to up-regulate SDF-1 expression in cultured astrocytes and endothelial cells (Wei et al., 2014). The expression of SDF-1 has been shown to affect disease process in many cardiovascular diseases.

In the heart, various cells including cardiomyocytes, stromal cells, endothelial cells, fibroblasts, and dendritic cells express SDF-1 (Wei et al., 2014). The wide distribution of SDF-1 in the heart witnesses to its important physiological roles and its roles in disease states. SDF-1 levels are shown to increase in many cardiac pathological conditions including myocardial ischemia, myocardial infarction, myocardial inflammation, atrial fibrillation, and the development of heart failure (Bromage et al., 2014; Wei et al., 2014; Li et al., 2016). Increased expression of platelet SDF-1 was shown to have negative clinical outcomes
(Rath et al., 2017). Since, elevated pro inflammatory cytokines such as TNF- $\alpha$ is linked to causing contractile dysfunction, apoptosis and remodeling in the heart (Chen et al., 2010). It could be indicated that elevated levels of both SDF-1 and TNF- $\alpha$ could have a synergistic effect in causing damage in cardiovascular disease.

SDF-1 alpha has also been shown to play roles in other disease conditions that affect other systems in the body commonly affected by heavy alcohol exposure. SDF-1 has been shown to increase in toxic liver damage, neonatal sepsis, autoimmune, inflammatory diseases, Helicobacter Pylori induced peptic ulcer, rotator cuff disease, skin inflammation squamous cell carcinoma of the lung, renal ischemia-reperfusion injury, glioblastoma tumor, and AIDS-associated neurologic disorders (Han et al., 2001; Rostasy et al., 2003; Kim et al., 2006; Bromage et al., 2014; Wan et al., 2014; Zgraggen et al., 2014; Seemann and Lupp, 2015; Bagheri et al., 2016; Sterlacci et al., 2016). The binding of SDF-1 to its receptor induces neuronal apoptosis in vitro, which indicates the pathological roles of SDF-1 in increasing the severity of neurological impairment due to increased astrocyte cell death (Table 1; Han et al., 2001). Moreover, it has been shown that through astrocytes, SDF-1 inductions of TNF- $\alpha$ provides a course of soluble cytotoxic factors that could induce neuronal cell death and contribute to the pathogenesis of HIV associated dementia (Han et al., 2001). Together, SDF-1 and TNF- $\alpha$ could promote and accelerate local inflammation and damage via their paracrine and autocrine mechanisms (Table 1).

Activation of TNF- $\alpha$ by SDF-1 has also been postulated to promote the reactivation of latent HIV in macrophages and microglial cells (Table 1; Han et al., 2001). Other papers have suggested that TNF- $\alpha$ induction of SDF-1 limits immune cells from entering the CNS (Table 1; Blazevski et al., 2015). However, the protective role for SDF-1 in injury, in particular alcoholinduced injuries are also suggested; when the alcohol induced alteration in circulating chemokines were explored in animal models, they noticed that rats exposed to repeated ethanol had lower SDF-1 and higher Eotaxin-1 (also known as CCL11) concentration in their plasma (Garcia-Marchena et al., 2016). Upregulation of SDF-1 is also associated with reduced size of alcoholic fatty liver transplants in which the action of SDF-1 was contributed to its role in mobilizing of host stem cells to the site of injury and aid in repair and successful transplantation (Hisada et al., 2012). The concerns still remains on whether increases in chemokines and/or cytokines leads to immune activation in remote organs such as the brain and the heart, whether they contribute to subsequent alcohol inflicted injuries, and whether they may have other important functions.

\section{CONCLUSION AND PERSPECTIVES}

Collectively, these data suggest that the alcohol induced alteration in circulating chemokines is a major contributor in alcoholic mediated organ damages via both direct and indirect mechanisms (Figure 1). The presented data suggests a link between the heavy drinking and an increase in the expression of SDF-1 and TNF- $\alpha$, however, whether they are involved 
in alcoholic mediated damage in CNS or heart is not clear and needs further studied. This is important because recently overexpression of SDF-1 via gene therapy was used as a strategy for improving heart failure symptoms in patients with ischemic cardiomyopathy (Penn et al., 2013). In this study, researchers tried to use the body's stem cell-based repair mechanism by drawing the patients' own stem cells to the site of injury using the effect of SDF-1. Even though the results seemed promising, there were some concerns, including the very small group of participants and the lack of placebo group. However, in a follow up study, the final 12-month results from the Phase 2 STOP-HF clinical trial, double-blind, randomized, placebo-controlled trial by Juventas Therapeutics demonstrated that in a population with advanced chronic heart failure who are symptomatic and present with poor cardiac function, a single administration of $30 \mathrm{mg}$ of JVS-100, non-viral DNA plasmid gene therapy of SDF-1, has the potential to improve cardiac function, but failed to demonstrate its primary endpoint of improved composite score at 4 months after treatment (Chung et al., 2015). Stem-cell therapy seems to be a promising approach against alcohol-induced cardiac or noncardiac systemic damages, however there are a number of hurdles in the path of stem cell research that has prevented the routine application of the technology in regenerative medicine.

In conclusion, alcohol's action are complex, chronic alcohol consumption can increase the risk of heart disease, brain damage, dementia, neuropathy, metabolic disturbances, nutritional deficiencies, certain cancers, liver, and other faces of morbidity and mortality. In this review we have highlighted the

\section{REFERENCES}

Abe, T., Su, C. A., Iida, S., Baldwin, W. M. III, Nonomura, N., Takahara, S., et al. (2014). Graft-derived CCL2 increases graft injury during antibodymediated rejection of cardiac allografts. Am. J. Transplant. 14, 1753-1764. doi: 10.1111/ajt.12780

Achur, R. N., Freeman, W. M., and Vrana, K. E. (2010). Circulating cytokines as biomarkers of alcohol abuse and alcoholism. J. Neuroimmune Pharmacol. 5, 83-91. doi: 10.1007/s11481-009-9185-Z

Adams, M. A., and Hirst, M. (1990). Metoprolol suppresses the development of ethanol-induced cardiac hypertrophy in the rat. Can. J. Physiol. Pharmacol. 68, 562-567. doi: 10.1139/y90-082

Aistrup, G. L., Kelly, J. E., Piano, M. R., and Wasserstrom, J. A. (2006). Biphasic changes in cardiac excitation-contraction coupling early in chronic alcohol exposure. Am. J. Physiol. Heart Circ. Physiol. 291, H1047-H1057. doi: 10.1152/ajpheart.00214.2006

Akiyama, H., Arai, T., Kondo, H., Tanno, E., Haga, C., and Ikeda, K. (2000a). Cell mediators of inflammation in the Alzheimer disease brain. Alzheimer Dis. Assoc. Disord. 14(Suppl. 1), S47-S53. doi: 10.1097/00002093-200000001-00008

Akiyama, H., Barger, S., Barnum, S., Bradt, B., Bauer, J., Cole, G. M., et al. (2000b). Inflammation and Alzheimer's disease. Neurobiol. Aging 21, 383-421. doi: 10.1016/S0197-4580(00)00124-X

Albert, C. M., Manson, J. E., Cook, N. R., Ajani, U. A., Gaziano, J. M., and Hennekens, C. H. (1999). Moderate alcohol consumption and the risk of sudden cardiac death among US male physicians. Circulation 100, 944-950. doi: 10.1161/01.CIR.100.9.944

Altura, B. M., Zou, L. Y., Altura, B. T., Jelicks, L., Wittenberg, B. A., and Gupta, R. K. (1996). Beneficial vs. detrimental actions of ethanol on heart and coronary vascular muscle: roles of $\mathrm{Mg}^{2+}$ and $\mathrm{Ca}^{2+}$. Alcohol 13, 499-513. doi: 10.1016/0741-8329(96)00044-4 contribution of inflammatory process in alcohol-mediated tissue damage and organ dysfunction. What is apparent from literature review is that the full understanding of the related cytokine signaling pathways in alcoholic injuries will be essential for further understanding of their potential contribution and their complex biological effects on alcohol-induced organ damage. Investigation of agents that interfere with inflammatory cytokine production is needed in order to enhance our understanding on their potential contributions into pathogenesis of diseases that are associated with excessive alcohol consumption.

\section{AUTHOR CONTRIBUTIONS}

$\mathrm{AO}$ and AP: performed the literature search and designed the tables/figures and edited the manuscript; ST: wrote the manuscript; JL and GH: performed the literature search and discussed the content of the manuscript.

\section{FUNDING}

This work was supported, in part by, (1) American Heart Association (GRNT4180006) and (2) National Institute of Minority Health and Health Disparities of the National Institutes of Health (G12MD007597). We would like to acknowledge the Howard University RCMI (Research Centers in Minority Institutions) and the HU-Advance-it society for providing helpful programs to address minority health and health disparities.

Aroor, A. R., and Shukla, S. D. (2004). MAP kinase signaling in diverse effects of ethanol. Life Sci. 74, 2339-2364. doi: 10.1016/j.lfs.2003.11.001

Aroor, A. R., Custer, G. W., Weng, Y. I., Lee, Y. J., and Shukla, S. D. (2002). Phosphotidylethanol mimics ethanol modulation of p42/44 mitogenactivated protein kinase signalling in hepatocytes. Alcohol Alcohol. 37, 534-539. doi: 10.1093/alcalc/37.6.534

Aukrust, P., Ueland, T., Müller, F., Andreassen, A. K., Nordoy, I., Aas, H., et al. (1998). Elevated circulating levels of C-C chemokines in patients with congestive heart failure. Circulation 97, 1136-1143. doi: 10.1161/01.CIR.97.12.1136

Bagheri, V., Hassanshahi, G., Mirzaee, V., and Khorramdelazad, H. (2016). CXC chemokine CXCL12 tissue expression and circulating levels in peptic ulcer patients with Helicobacter pylori infection. Cytokine 85, 1-4. doi: 10.1016/j.cyto.2016.05.025

Bamji, Z. D., and Haddad, G. E. (2015). Convergence of theories of alcohol administration postanabolic stimulation on mTOR signaling: lessons for exercise regimen. Alcohol. Clin. Exp. Res. 39, 787-789. doi: 10.1111/acer.12702

Banks, A. D. (2008). Women and heart disease: missed opportunities. J. Midwifery Womens. Health 53, 430-439. doi: 10.1016/j.jmwh.2008.04.008

Bauer, S., Cepok, S., Todorova-Rudolph, A., Nowak, M., Köller, M., Lorenz, R., et al. (2009). Etiology and site of temporal lobe epilepsy influence postictal cytokine release. Epilepsy Res. 86, 82-88. doi: 10.1016/j.eplepsyres.2009.05.009

Baumgartner, K. B., Annegers, J. F., McPherson, R. S., Frankowski, R. F., Gilliland, F. D., and Samet, J. M. (2002). Is alcohol intake associated with breast cancer in Hispanic women? The New Mexico Women's Health Study. Ethn. Dis. 12, 460-469.

Berger, K., Ajani, U. A., Kase, C. S., Gaziano, J. M., Buring, J. E., Glynn, R. J., et al. (1999). Light-to-moderate alcohol consumption and the risk of stroke among U.S. male physicians. N. Engl. J. Med. 341, 1557-1564. doi: 10.1056/NEJM199911183412101 
Blaževski, J., Petković, F., Momcilović, M., Jevtić, B., Mostarica Stojkovic, M., and Miljković, D. (2015). Tumor necrosis factor stimulates expression of CXCL12 in astrocytes. Immunobiology 220, 845-850. doi: 10.1016/j.imbio.2015.01.007

Bommiasamy, H., Back, S. H., Fagone, P., Lee, K., Meshinchi, S., Vink, E., et al. (2009). ATF6alpha induces XBP1-independent expansion of the endoplasmic reticulum. J. Cell Sci. 122, 1626-1636. doi: 10.1242/jcs.045625

Braunersreuther, V., Pellieux, C., Pelli, G., Burger, F., Steffens, S., Montessuit, C., et al. (2010). Chemokine CCL5/RANTES inhibition reduces myocardial reperfusion injury in atherosclerotic mice. J. Mol. Cell. Cardiol. 48, 789-798. doi: 10.1016/j.yjmcc.2009.07.029

Breder, C. D., Tsujimoto, M., Terano, Y., Scott, D. W., and Saper, C. B. (1993). Distribution and characterization of tumor necrosis factor-alpha-like immunoreactivity in the murine central nervous system. J. Comp. Neurol. 337, 543-567. doi: 10.1002/cne. 903370403

Bromage, D. I., Davidson, S. M., and Yellon, D. M. (2014). Stromal derived factor $1 \alpha$ : a chemokine that delivers a two-pronged defence of the myocardium. Pharmacol. Ther. 143, 305-315. doi: 10.1016/j.pharmthera.2014.03.009

Brown, R. A., Sundareson, A. M., Lee, M. M., and Savage, A. O. (1996). Differential effects of chronic calcium channel blocker treatment on the inotropic response of diabetic rat myocardium to acute ethanol exposure. Life Sci. 59, 835-847. doi: 10.1016/0024-3205(96)00374-8

Bryant, D., Becker, L., Richardson, J., Shelton, J., Franco, F., Peshock, R., et al. (1998). Cardiac failure in transgenic mice with myocardial expression of tumor necrosis factor-alpha. Circulation 97, 1375-1381. doi: 10.1161/01.CIR.97.14.1375

Cacciapaglia, F., Salvatorelli, E., Minotti, G., Afeltra, A., and Menna, P. (2014). Low level tumor necrosis factor-alpha protects cardiomyocytes against high level tumor necrosis factor-alpha: brief insight into a beneficial paradox. Cardiovasc. Toxicol. 14, 387-392. doi: 10.1007/s12012-014-9257-z

Cervilla, J. A., Prince, M., Joels, S., Lovestone, S., and Mann, A. (2000). Long-term predictors of cognitive outcome in a cohort of older people with hypertension. Br. J. Psychiatry 177, 66-71. doi: 10.1192/bjp.177.1.66

Chen, D. B., Wang, L., and Wang, P. H. (2000). Insulin-like growth factor I retards apoptotic signaling induced by ethanol in cardiomyocytes. Life Sci. 67, 1683-1693. doi: 10.1016/S0024-3205(00)00759-1

Chen, J., Chemaly, E., Liang, L., Kho, C., Lee, A., Park, J., et al. (2010). Effects of CXCR4 gene transfer on cardiac function after ischemia-reperfusion injury. Am. J. Pathol. 176, 1705-1715. doi: 10.2353/ajpath.2010.090451

Chen, Y. J., Zhu, J. M., Wu, H., Fan, J., Zhou, J., Hu, J., et al. (2013). Circulating microRNAs as a fingerprint for liver cirrhosis. PLoS ONE 8:e66577. doi: 10.1371/journal.pone.0066577

Chen, Y. P., Jin, X., Xiang, Z., Chen, S. H., and Li, Y. M. (2013). Circulating MicroRNAs as potential biomarkers for alcoholic steatohepatitis. Liver Int. 33, 1257-1265. doi: 10.1111/liv.12196

Choi, C., Jeong, J. H., Jang, J. S., Choi, K., Lee, J., Kwon, J., et al. (2008). Multiplex analysis of cytokines in the serum and cerebrospinal fluid of patients with Alzheimer's disease by color-coded bead technology. J. Clin. Neurol. 4, 84-88. doi: $10.3988 /$ jcn.2008.4.2.84

Chung, E. S., Miller, L., Patel, A. N., Anderson, R. D., Mendelsohn, F. O., Traverse, J., et al. (2015). Changes in ventricular remodelling and clinical status during the year following a single administration of stromal cellderived factor-1 non-viral gene therapy in chronic ischaemic heart failure patients: the STOP-HF randomized Phase II trial. Eur. Heart J. 36, 2228-2238. doi: 10.1093/eurheartj/ehv254

Crews, F. T., Collins, M. A., Dlugos, C., Littleton, J., Wilkins, L., Neafsey, E. J., et al. (2004). Alcohol-induced neurodegeneration: when, where and why? Alcohol. Clin. Exp. Res. 28, 350-364. doi: 10.1097/01.ALC.0000113416.65546.01

Crews, F. T., Sarkar, D. K., Qin, L., Zou, J., Boyadjieva, N., and Vetreno, R. P. (2015). Neuroimmune function and the consequences of alcohol exposure. Alcohol Res. 37, 331-341, 344-351.

Da Silva, A. L., Ruginsk, S. G., Uchoa, E. T., Crestani, C. C., Scopinho, A. A., Correa, F. M., et al. (2013). Time-course of neuroendocrine changes and its correlation with hypertension induced by ethanol consumption. Alcohol Alcohol. 48, 495-504. doi: 10.1093/alcalc/agt040

Danziger, R. S., Sakai, M., Capogrossi, M. C., Spurgeon, H. A., Hansford, R. G., and Lakatta, E. G. (1991). Ethanol acutely and reversibly suppresses excitation-contraction coupling in cardiac myocytes. Circ. Res. 68, 1660-1668. doi: 10.1161/01.RES.68.6.1660
Djoussé, L., and Gaziano, J. M. (2008a). Alcohol consumption and heart failure in hypertensive US male physicians. Am. J. Cardiol. 102, 593-597. doi: 10.1016/j.amjcard.2008.04.031

Djoussé, L., and Gaziano, J. M. (2008b). Alcohol consumption and heart failure: a systematic review. Curr. Atheroscler. Rep. 10, 117-120. doi: $10.1007 / \mathrm{s} 11883-008-0017-\mathrm{z}$

Djousse, L., Arnett, D. K., Eckfeldt, J. H., Province, M. A., Singer, M. R., and Ellison, R. C. (2004a). Alcohol consumption and metabolic syndrome: does the type of beverage matter? Obes. Res. 12, 1375-1385. doi: 10.1038/oby.2004.174

Djoussé, L., Levy, D., Benjamin, E. J., Blease, S. J., Russ, A., Larson, M. G., et al. (2004b). Long-term alcohol consumption and the risk of atrial fibrillation in the Framingham Study. Am. J. Cardiol. 93, 710-713. doi: 10.1016/j.amjcard.2003.12.004

Doe, C., Bentley, R., Behm, D. J., Lafferty, R., Stavenger, R., Jung, D., et al. (2007). Novel Rho kinase inhibitors with anti-inflammatory and vasodilatory activities. J. Pharmacol. Exp. Ther. 320, 89-98. doi: 10.1124/jpet.106.110635

Dopico, A. M. (2003). Ethanol sensitivity of BK(Ca) channels from arterial smooth muscle does not require the presence of the beta 1-subunit. Am. J. Physiol. Cell Physiol. 284, C1468-C1480. doi: 10.1152/ajpcell.00421.2002

Döring, Y., Pawig, L., Weber, C., and Noels, H. (2014). The CXCL12/CXCR4 chemokine ligand/receptor axis in cardiovascular disease. Front. Physiol. 5:212. doi: $10.3389 /$ fphys.2014.00212

Dubowski, K. M. (1985). Absorption, distribution and elimination of alcohol: highway safety aspects. J. Stud. Alcohol Suppl. 10, 98-108. doi: $10.15288 /$ jsas.1985.s10.98

Eckardt, M. J., File, S. E., Gessa, G. L., Grant, K. A., Guerri, C., Hoffman, P. L., et al. (1998). Effects of moderate alcohol consumption on the central nervous system. Alcohol. Clin. Exp. Res. 22, 998-1040. doi: 10.1111/j.1530-0277.1998.tb0 3695.x

Estruch, R., Nicolás, J. M., Villegas, E., Junqué, A., and Urbano-Márquez, A. (1993). Relationship between ethanol-related diseases and nutritional status in chronically alcoholic men. Alcohol Alcohol. 28, 543-550.

Faris, R. F., Henein, M. Y., and Coats, A. J. (2003). Influence of gender and reported alcohol intake on mortality in nonischemic dilated cardiomyopathy. Heart Dis. 5, 89-94. doi: 10.1097/01.HDX.0000061702.79961.47

Feldman, A. M., Combes, A., Wagner, D., Kadakomi, T., Kubota, T., Li, Y. Y., et al. (2000). The role of tumor necrosis factor in the pathophysiology of heart failure. J. Am. Coll. Cardiol. 35, 537-544. doi: 10.1016/S0735-1097(99)0 0600-2

Feng, L., Nian, S. Y., Hao, Y. L., Xu, W. B., Ye, D., Zhang, X. F., et al. (2014). A single nucleotide polymorphism in the stromal cell-derived factor 1 gene is associated with coronary heart disease in Chinese patients. Int. J. Mol. Sci. 15, 11054-11063. doi: 10.3390/ijms150611054

Fernandez-Lizarbe, S., Montesinos, J., and Guerri, C. (2013). Ethanol induces TLR4/TLR2 association, triggering an inflammatory response in microglial cells. J. Neurochem. 126, 261-273. doi: 10.1111/jnc.12276

Fernández-Solà, J., and Planavila Porta, A. (2016). New treatment strategies for alcohol-induced heart damage. Int. J. Mol. Sci. 17:E1651. doi: 10.3390/ijms17101651

Fernández-Solà, J., Fatjó, F., Sacanella, E., Estruch, R., Bosch, X., Urbano-Marquez, A., et al. (2006). Evidence of apoptosis in alcoholic cardiomyopathy. Hum. Pathol. 37, 1100-1110. doi: 10.1016/j.humpath.2006.03.022

Ferrari, R. (1999). The role of TNF in cardiovascular disease. Pharmacol. Res. 40, 97-105. doi: 10.1006/phrs.1998.0463

Garcia-Marchena, N., Araos, P. F., Barrios, V., Sanchez-Marin, L., Chowen, J. A., Pedraz, M., et al. (2016). Plasma chemokines in patients with alcohol use disorders: association of CCL11 (Eotaxin-1) with psychiatric comorbidity. Front. Psychiatry 7:214. doi: 10.3389/fpsyt.2016.00214

Gezen-Ak, D., Dursun, E., Hanagasi, H., Bilgic, B., Lohman, E., Araz, O. S., et al. (2013). BDNF, TNFalpha, HSP90, CFH, and IL-10 serum levels in patients with early or late onset Alzheimer's disease or mild cognitive impairment. J. Alzheimers Dis. 37, 185-195. doi: 10.3233/JAD-130497

Gordon, J. R., Burd, P. R., and Galli, S. J. (1990). Mast cells as a source of multifunctional cytokines. Immunol. Today 11, 458-464. doi: 10.1016/0167-5699(90)90176-A

Guo, R., Hu, N., Kandadi, M. R., and Ren, J. (2012). Facilitated ethanol metabolism promotes cardiomyocyte contractile dysfunction through autophagy in murine hearts. Autophagy 8, 593-608. doi: 10.4161/auto. 18997 
Guzzo-Merello, G., Segovia, J., Dominguez, F., Cobo-Marcos, M., Gomez-Bueno, M., Avellana, P., et al. (2015). Natural history and prognostic factors in alcoholic cardiomyopathy. JACC Heart Fail. 3, 78-86. doi: 10.1016/j.jchf.2014.07.014

Haddad, G. E., Saunders, L., Carles, M., Crosby, S. D., del Monte, F., MacGillivray, T. E., et al. (2008). Fingerprint profile of alcohol-associated heart failure in human hearts. Alcohol. Clin. Exp. Res. 32, 814-821. doi: 10.1111/j.1530-0277.2008.00628.x

Han, Y., He, T., Huang, D. R., Pardo, C. A., and Ransohoff, R. M. (2001). TNF-alpha mediates SDF-1 alpha-induced NF-kappa B activation and cytotoxic effects in primary astrocytes. J. Clin. Invest. 108, 425-435. doi: 10.1172/JCI12629

Hansson, G. K., Libby, P., Schönbeck, U., and Yan, Z. Q. (2002). Innate and adaptive immunity in the pathogenesis of atherosclerosis. Circ. Res. 91, 281-291. doi: 10.1161/01.RES.0000029784.15893.10

Hartzler, B., and Fromme, K. (2003). Fragmentary and en bloc blackouts: similarity and distinction among episodes of alcohol-induced memory loss. J. Stud. Alcohol 64, 547-550. doi: 10.15288/jsa.2003.64.547

Heberto Herrera Garza, E., Herrera Garza, J. L., Rodríguez González, H., Treviño Treviño, A., Ibarra Flores, M., and Torre Amione, G. (2002). [Importance of tumor necrosis factor-alpha in the pathogenesis of heart failure]. Rev. Esp. Cardiol. 55, 61-66. doi: 10.1016/S0300-8932(02)76554-8

Hisada, M., Ota, Y., Zhang, X., Cameron, A. M., Gao, B., Montgomery, R. A., et al. (2012). Successful transplantation of reduced-sized rat alcoholic fatty livers made possible by mobilization of host stem cells. Am. J. Transplant 12, 3246-3256. doi: 10.1111/j.1600-6143.2012.04265.x

Hommer, D. W. (2003). Male and female sensitivity to alcohol-induced brain damage. Alcohol Res. Health 27, 181-185.

Husebye, T., Eritsland, J., Arnesen, H., Bjornerheim, R., Mangschau, A., Seljeflot, I., et al. (2014). Association of interleukin 8 and myocardial recovery in patients with ST-elevation myocardial infarction complicated by acute heart failure. PLoS ONE 9:e112359. doi: 10.1371/journal.pone.0112359

Janelsins, M. C., Mastrangelo, M. A., Park, K. M., Sudol, K. L., Narrow, W. C., Oddo, S., et al. (2008). Chronic neuron-specific tumor necrosis factoralpha expression enhances the local inflammatory environment ultimately leading to neuronal death in 3xTg-AD mice. Am. J. Pathol. 173, 1768-1782. doi: 10.2353/ajpath.2008.080528

Jänkälä, H., Eklund, K. K., Kokkonen, J. O., Kovanen, P. T., Linstedt, K. A., Harkonen, M., et al. (2001). Ethanol infusion increases ANP and p21 gene expression in isolated perfused rat heart. Biochem. Biophys. Res. Commun. 281, 328-333. doi: 10.1006/bbrc. 2001.4343

Ji, C. (2012). Mechanisms of alcohol-induced endoplasmic reticulum stress and organ injuries. Biochem. Res. Int. 2012:216450. doi: 10.1155/2012/216450

Jing, L., Jin, C., Lu, Y., Huo, P., Zhou, L., Wang, Y., et al. (2015). Investigation of microRNA expression profiles associated with human alcoholic cardiomyopathy. Cardiology 130, 223-233. doi: 10.1159/000370028

Jougasaki, M. (2010). Cardiotrophin-1 in cardiovascular regulation. Adv. Clin. Chem. 52, 41-76. doi: 10.1016/S0065-2423(10)52002-X

Kagan, A., Yano, K., Reed, D. M., and MacLean, C. J. (1989). Predictors of sudden cardiac death among Hawaiian-Japanese men. Am. J. Epidemiol. 130, 268-277. doi: 10.1093/oxfordjournals.aje.a115333

Kähkönen, S., Wilenius, J., Nikulin, V. V., Ollikainen, M., and Ilmoniemi, R. J. (2003). Alcohol reduces prefrontal cortical excitability in humans: a combined TMS and EEG study. Neuropsychopharmacology 28, 747-754. doi: 10.1038/sj.npp.1300099

Kannan, M., Wang, L., and Kang, Y. J. (2004). Myocardial oxidative stress and toxicity induced by acute ethanol exposure in mice. Exp. Biol. Med. 229, 553-559. doi: 10.1177/153537020422900614

Kannel, W. B. (1998). Overview of atherosclerosis. Clin. Ther. 20(Suppl. B), B2-B17.

Ke, Z., Wang, X., Liu, Y., Fan, Z., Chen, G., Xu, M., et al. (2011). Ethanol induces endoplasmic reticulum stress in the developing brain. Alcohol. Clin. Exp. Res. 35, 1574-1583. doi: 10.1111/j.1530-0277.2011.01503.x

Keenan, J. P., Freeman, P. R., and Harrell, R. (1997). The effects of family history, sobriety length, and drinking history in younger alcoholics on P300 auditory-evoked potentials. Alcohol Alcohol. 32, 233-239. doi: 10.1093/oxfordjournals.alcalc.a008262

Kim, Y. S., Bigliani, L. U., Fujisawa, M., Murakami, K., Chang, S. S., Lee, H. J., et al. (2006). Stromal cell-derived factor 1 (SDF-1, CXCL12) is increased in subacromial bursitis and downregulated by steroid and nonsteroidal antiinflammatory agents. J. Orthop. Res. 24, 1756-1764. doi: 10.1002/jor.20197

Lai, Y. J., Hung, C. L., Hong, R. C., Tseng, Y. M., Lin, C. I., Ko, Y. S., et al. (2011). Slow conduction and gap junction remodeling in murine ventricle after chronic alcohol ingestion. J. Biomed. Sci. 18, 72. doi: 10.1186/1423-012718-72

LaRocca, T. J., Schwarzkopf, M., Altman, P., Zhang, S., Gupta, A., Gomes, I., et al. (2010). beta2-Adrenergic receptor signaling in the cardiac myocyte is modulated by interactions with CXCR4. J. Cardiovasc. Pharmacol. 56, 548-559. doi: 10.1097/FJC.0b013e3181f713fe

Latif, O., Peterson, J. D., and Waltenbaugh, C. (2002). Alcohol-mediated polarization of type 1 and type 2 immune responses. Front. Biosci. 7, a135-147.

Leaf, A., Kang, J. X., Xiao, Y. F., and Billman, G. E. (2003). Clinical prevention of sudden cardiac death by $n-3$ polyunsaturated fatty acids and mechanism of prevention of arrhythmias by n-3 fish oils. Circulation 107, 2646-2652. doi: 10.1161/01.CIR.0000069566.78305.33

Lee, Y. B., Nagai, A., and Kim, S. U. (2002). Cytokines, chemokines, and cytokine receptors in human microglia. J. Neurosci. Res. 69, 94-103. doi: 10.1002/jnr.10253

Lemstra, M., Bennett, N. R., Neudorf, C., Kunst, A., Nannapaneni, U., Warren, L. M., et al. (2008). A meta-analysis of marijuana and alcohol use by socioeconomic status in adolescents aged 10-15 years. Can. J. Public Health 99, $172-177$.

Lertkiatmongkol, P., Liao, D., Mei, H., Hu, Y., and Newman, P. J. (2016) Endothelial functions of platelet/endothelial cell adhesion molecule-1 (CD31). Curr. Opin. Hematol. 23, 253-259. doi: 10.1097/MOH.0000000000000239

Li, D., Bjornager, L., Langkilde, A., Andersen, O., Jons, C., Agner, B. F., et al. (2016). Stromal cell-derived factor lalpha (SDF-1alpha): a marker of disease burden in patients with atrial fibrillation. Scand. Cardiovasc. J. 50, 36-41. doi: 10.3109/14017431.2015.1103892

Li, S. Y., and Ren, J. (2008). Cardiac overexpression of alcohol dehydrogenase exacerbates chronic ethanol ingestion-induced myocardial dysfunction and hypertrophy: role of insulin signaling and ER stress. J. Mol. Cell. Cardiol. 44, 992-1001. doi: 10.1016/j.yjmcc.2008.02.276

Li, S. Y., Li, Q., Shen, J. J., Dong, F., Sigmon, V. K., Liu, Y., et al. (2006). Attenuation of acetaldehyde-induced cell injury by overexpression of aldehyde dehydrogenase-2 (ALDH2) transgene in human cardiac myocytes: role of MAP kinase signaling. J. Mol. Cell. Cardiol. 40, 283-294. doi: 10.1016/j.yjmcc.2005.11.006

Lieber, C. S. (1990). Mechanism of ethanol induced hepatic injury. Pharmacol. Ther. 46, 1-41. doi: 10.1016/0163-7258(90)90032-W

Lippai, D., Bala, S., Csak, T., Kurt-Jones, E. A., and Szabo, G. (2013). Chronic alcohol-induced microRNA-155 contributes to neuroinflammation in a TLR4-dependent manner in mice. PLoS ONE 8:e70945. doi: 10.1371/journal.pone.0070945

Liu, J., Lewohl, J. M., Dodd, P. R., Randall, P. K., Harris, R. A., and Mayfield, R. D. (2004). Gene expression profiling of individual cases reveals consistent transcriptional changes in alcoholic human brain. J. Neurochem. 90, 1050-1058. doi: 10.1111/j.1471-4159.2004.02570.x

Liu, J., Lewohl, J. M., Harris, R. A., Iyer, V. R., Dodd, P. R., Randall, P. K., et al. (2006). Patterns of gene expression in the frontal cortex discriminate alcoholic from nonalcoholic individuals. Neuropsychopharmacology 31, 1574-1582. doi: 10.1038/sj.npp.1300947

Liu, P., Liu, J., Huang, W., Li, M. D., and Dopico, A. M. (2003). Distinct regions of the slo subunit determine differential BKCa channel responses to ethanol. Alcohol. Clin. Exp. Res. 27, 1640-1644. doi: 10.1097/01.ALC.0000094756.41638.5D

Louvet, A., and Mathurin, P. (2015). Alcoholic liver disease: mechanisms of injury and targeted treatment. Nat. Rev. Gastroenterol. Hepatol. 12, 231-242. doi: 10.1038/nrgastro.2015.35

Lundberg, J. C., and Passik, S. D. (1997). Alcohol and cancer: a review for psycho-oncologists. Psychooncology 6, 253-266.

MacHackova, J., Barta, J., and Dhalla, N. S. (2006). Myofibrillar remodeling in cardiac hypertrophy, heart failure and cardiomyopathies. Can. J. Cardiol. 22, 953-968. doi: 10.1016/S0828-282X(06)70315-4

Mailloux, R. J. (2016). Application of mitochondria-targeted pharmaceuticals for the treatment of heart disease. Curr. Pharm. Des. 22, 4763-4779. doi: $10.2174 / 1381612822666160629070914$ 
Mandyam, C. D., Villalpando, E. G., Steiner, N. L., Quach, L. W., Fannon, M. J., and Somkuwar, S. S. (2017). Platelet endothelial cell adhesion molecule-1 and oligodendrogenesis: significance in alcohol use disorders. Brain Sci. 7:E131. doi: 10.3390/brainsci7100131

Manzo-Avalos, S., and Saavedra-Molina, A. (2010). Cellular and mitochondrial effects of alcohol consumption. Int. J. Environ. Res. Public Health 7, 4281-4304. doi: 10.3390/ijerph7124281

McAlpine, F. E., Lee, J. K., Harms, A. S., Ruhn, K. A., Blurton-Jones, M., Hong, J., et al. (2009). Inhibition of soluble TNF signaling in a mouse model of Alzheimer's disease prevents pre-plaque amyloid-associated neuropathology. Neurobiol. Dis. 34, 163-177. doi: 10.1016/j.nbd.2009.01.006

McCoy, M. K., and Tansey, M. G. (2008). TNF signaling inhibition in the CNS: implications for normal brain function and neurodegenerative disease. J. Neuroinflammation 5, 45. doi: 10.1186/1742-2094-5-45

Meadows, G. G., Wallendal, M., Kosugi, A., Wunderlich, J., and Singer, D. S. (1992). Ethanol induces marked changes in lymphocyte populations and natural killer cell activity in mice. Alcohol. Clin. Exp. Res. 16, 474-479. doi: 10.1111/j.1530-0277.1992.tb01403.x

Meldrum, D. R., Cleveland, J. C. Jr., Cain, B. S., Meng, X., and Harken, A. H. (1998). Increased myocardial tumor necrosis factor-alpha in a crystalloid-perfused model of cardiac ischemia-reperfusion injury. Ann. Thorac. Surg. 65, 439-443. doi: 10.1016/S0003-4975(97)01297-6

Moiseev, V. S., Goncharov, A. S., Terebilina, N. N., Panchenko, L. F., Kiiakbaev, G. K., Traianova, T. G., et al. (2013). [Immunoinflammatory changes (myocarditis?) in chronic heart failure in alcoholic patients]. Ter. Arkh. 85, 27-35.

Moss, M., Parsons, P. E., Steinberg, K. P., Hudson, L. D., Guidot, D. M., Burnham, E. L., et al. (2003). Chronic alcohol abuse is associated with an increased incidence of acute respiratory distress syndrome and severity of multiple organ dysfunction in patients with septic shock. Crit. Care Med. 31, 869-877. doi: 10.1097/01.CCM.0000055389.64497.11

Muñoz-Fernández, M. A., and Fresno, M. (1998). The role of tumour necrosis factor, interleukin 6, interferon-gamma and inducible nitric oxide synthase in the development and pathology of the nervous system. Prog. Neurobiol. 56, 307-340. doi: 10.1016/S0301-0082(98)00045-8

Nakamura, K., Kouchi, H., Ohe, T., and Namba, M. (1999). Increase in beating rate of cultured chick cardiac myocytes by ethanol and inhibition of the increase by antiarrhythmic drugs. Alcohol. Clin. Exp. Res. 23, 81S-84S. doi: 10.1111/j.1530-0277.1999.tb04540.x

Natarajan, S. K., Pachunka, J. M., and Mott, J. L. (2015). Role of microRNAs in alcohol-induced multi-organ injury. Biomolecules 5, 3309-3338. doi: 10.3390/biom5043309

Nicolás, J. M., Fernández-Solá, J., Estruch, R., Paré, J. C., Sacanella, E., Urbano-Marquez, A., et al. (2002). The effect of controlled drinking in alcoholic cardiomyopathy. Ann. Intern. Med. 136, 192-200. doi: 10.7326/0003-4819-136-3-200202050-00007

Nixon, K. (2006). Alcohol and adult neurogenesis: roles in neurodegeneration and recovery in chronic alcoholism. Hippocampus 16, 287-295. doi: 10.1002/hipo.20162

Nolen-Hoeksema, S., and Hilt, L. (2006). Possible contributors to the gender differences in alcohol use and problems. J. Gen. Psychol. 133, 357-374. doi: 10.3200/GENP.133.4.357-374

Okvist, A., Johansson, S., Kuzmin, A., Bazov, I., Merino-Martinez, R., Ponomarev, I., et al. (2007). Neuroadaptations in human chronic alcoholics: dysregulation of the NF-кB system. PLoS ONE 2:e930. doi: 10.1371/journal.pone.0000930

Oscar-Berman, M., and Bowirrat, A. (2005). Genetic influences in emotional dysfunction and alcoholism-related brain damage. Neuropsychiatr. Dis. Treat. 1, 211-229.

Oscar-Berman, M., and Pulaski, J. L. (1997). Association learning and recognition memory in alcoholic Korsakoff patients. Neuropsychology 11, 282-289. doi: 10.1037/0894-4105.11.2.282

Oz, M. C., Liao, H., Naka, Y., Seldomridge, A., Becker, D. N., Michler, R. E., et al. (1995). Ischemia-induced interleukin-8 release after human heart transplantation. A potential role for endothelial cells. Circulation 92, II428III32.

Panagiotakos, D. B., Pitsavos, C., Chrysohoou, C., Stefanadis, C., and Toutouzas, P. (2001). Risk stratification of coronary heart disease through established and emerging lifestyle factors in a Mediterranean population:
CARDIO2000 epidemiological study. J. Cardiovasc. Risk 8, 329-335 doi: 10.1177/174182670100800601

Panchenko, L. F., Moiseev, V. S., Pirozhkov, S. V., Terebilina, N. N., Naumova, T. A., Baronets, V., et al. (2015). [Blood content of markers of inflammation and cytokines in patients with alcoholic cardiomyopathy and ischemic heart disease at various stages of heart failure]. Kardiologiia 55, 41-48. doi: 10.18565/cardio.2015.3.41-48

Patel, V. B., Corbett, J. M., Dunn, M. J., Winrow, V. R., Portmann, B., Richardson, P. J., et al. (1997a). Protein profiling in cardiac tissue in response to the chronic effects of alcohol. Electrophoresis 18, 2788-2794. doi: 10.1002/elps.1150181513

Patel, V. B., Why, H. J., Richardson, P. J., and Preedy, V. R. (1997b). The effects of alcohol on the heart. Adv. Drug React. Toxicol. Rev. 16, 15-43.

Pecherskaya, A., Rubin, E., and Solem, M. (2002). Alterations in insulin-like growth factor-I signaling in cardiomyocytes from chronic alcohol-exposed rats. Alcohol. Clin. Exp. Res. 26, 995-1002. doi: 10.1111/j.1530-0277.2002.tb02633.x

Penn, M. S., Mendelsohn, F. O., Schaer, G. L., Sherman, W., Farr, M., Pastore, J., et al. (2013). An open-label dose escalation study to evaluate the safety of administration of nonviral stromal cell-derived factor-1 plasmid to treat symptomatic ischemic heart failure. Circ. Res. 112, 816-825. doi: 10.1161/CIRCRESAHA.111.300440

Pickering, M., Cumiskey, D., and O'Connor, J. J. (2005). Actions of TNF-alpha on glutamatergic synaptic transmission in the central nervous system. Exp. Physiol. 90, 663-670. doi: 10.1113/expphysiol.2005.030734

Pitossi, F., del Rey, A., Kabiersch, A., and Besedovsky, H. (1997). Induction of cytokine transcripts in the central nervous system and pituitary following peripheral administration of endotoxin to mice. J Neurosci Res 48, 287-298.

Preedy, V. R., Ohlendieck, K., Adachi, J., Koll, M., Sneddon, A., Hunter, R., et al. (2003). The importance of alcohol-induced muscle disease. J. Muscle Res. Cell Motil. 24, 55-63. doi: 10.1023/A:1024842817060

Privratsky, J. R., Newman, D. K., and Newman, P. J. (2010). PECAM-1: conflicts of interest in inflammation. Life Sci. 87, 69-82. doi: 10.1016/j.lfs.2010.06.001

Qin, L., He, J., Hanes, R. N., Pluzarev, O., Hong, J. S., and Crews, F. T. (2008). Increased systemic and brain cytokine production and neuroinflammation by endotoxin following ethanol treatment. J. Neuroinflammation 5:10. doi: 10.1186/1742-2094-5-10

Rath, D., Chatterjee, M., Bongartz, A., Muller, K., Droppa, M., Stimpfle, F., et al. (2017). Platelet surface expression of SDF-1 is associated with clinical outcomes in the patients with cardiovascular disease. Platelets 28, 34-39. doi: 10.1080/09537104.2016.1203399

Remick, D. (2013). Use of animal models for the study of human disease-a shock society debate. Shock 40, 345-346. doi: 10.1097/SHK.0b013e3182a2aee0

Ren, J. (2007). Interaction between high-fat diet and alcohol dehydrogenase on ethanol-elicited cardiac depression in murine myocytes. Obesity 15, 2932-2941. doi: 10.1038/oby.2007.350

Richardson, P. J., Wodak, A. D., Atkinson, L., Saunders, J. B., and Jewitt, D. E. (1986). Relation between alcohol intake, myocardial enzyme activity, and myocardial function in dilated cardiomyopathy. Evidence for the concept of alcohol induced heart muscle disease. Br. Heart J. 56, 165-170. doi: $10.1136 /$ hrt.56.2.165

Rimm, E. B., Stampfer, M. J., Ascherio, A., Giovannucci, E., Colditz, G. A., and Willett, W. C. (1993). Vitamin E consumption and the risk of coronary heart disease in men. N. Engl. J. Med. 328, 1450-1456. doi: 10.1056/NEJM199305203282004

Roderburg, C., and Luedde, T. (2014). Circulating microRNAs as markers of liver inflammation, fibrosis and cancer. J. Hepatol. 61, 1434-1437. doi: 10.1016/j.jhep.2014.07.017

Rodriguez, D. A., Moncada, C., Nunez, M. T., Lavandero, S., Ponnappa, B. C., and Israel, Y. (2004). Ethanol increases tumor necrosis factor-alpha receptor1 (TNF-R1) levels in hepatic, intestinal, and cardiac cells. Alcohol 33, 9-15. doi: 10.1016/S0741-8329(04)00056-4

Romeo, J., Warnberg, J., Nova, E., Diaz, L. E., Gomez-Martinez, S., and Marcos, A. (2007). Moderate alcohol consumption and the immune system: a review. Br. J. Nutr. 98(Suppl. 1), S111-S115. doi: 10.1017/S0007114507838049

Rostasy, K., Egles, C., Chauhan, A., Kneissl, M., Bahrani, P., Yiannoutsos, C., et al. (2003). SDF-1alpha is expressed in astrocytes and neurons in the AIDS dementia complex: an in vivo and in vitro study. J. Neuropathol. Exp. Neurol. 62, 617-626. doi: 10.1093/jnen/ 62.6.617 
Seemann, S., and Lupp, A. (2015). Administration of a CXCL12 analog in endotoxemia is associated with anti-inflammatory, antioxidative and cytoprotective effects in vivo. PLoS ONE10:e0138389. doi: 10.1371/journal.pone.0138389

Sempos, C. T., Rehm, J., Wu, T., Crespo, C. J., and Trevisan, M. (2003). Average volume of alcohol consumption and all-cause mortality in African Americans: the NHEFS cohort. Alcohol. Clin. Exp. Res. 27, 88-92. doi: 10.1111/j.1530-0277.2003.tb02726.x

Sheng, W., Zong, Y., Mohammad, A., Ajit, D., Cui, J., Han, D., et al. (2011). Pro-inflammatory cytokines and lipopolysaccharide induce changes in cell morphology, and upregulation of ERK1/2, iNOS and sPLA(2)IIA expression in astrocytes and microglia. J. Neuroinflammation 8:121. doi: 10.1186/1742-2094-8-121

Shirpoor, A., Nemati, S., Ansari, M. H., and Ilkhanizadeh, B. (2015). The protective effect of vitamin $\mathrm{E}$ against prenatal and early postnatal ethanol treatment-induced heart abnormality in rats: a 3-month follow-up study. Int. Immunopharmacol. 26, 72-79. doi: 10.1016/j.intimp.2015.03.008

Solem, M., Almas, J., Rubin, E., and Thomas, A. (2000). Changes in activity and regulation of the cardiac $\mathrm{Ca} 2+$ channel (L-type) by protein kinase C in chronic alcohol-exposed rats. Alcohol. Clin. Exp. Res. 24, 1145-1152. doi: 10.1111/j.1530-0277.2000.tb02077.x

Song, B. J., Akbar, M., Abdelmegeed, M. A., Byun, K., Lee, B., Yoon, S. K., et al. (2014). Mitochondrial dysfunction and tissue injury by alcohol, high fat, nonalcoholic substances and pathological conditions through post-translational protein modifications. Redox Biol. 3, 109-123. doi: 10.1016/j.redox.2014.10.004

Sparagna, G. C., Jones, C. E., and Hickson-Bick, D. L. (2004). Attenuation of fatty acid-induced apoptosis by low-dose alcohol in neonatal rat cardiomyocytes. Am. J. Physiol. Heart Circ. Physiol. 287, H2209-H2215. doi: 10.1152/ajpheart.00247.2004

Spitzer, J. H., and Meadows, G. G. (1999). Modulation of perforin, granzyme A, and granzyme B in murine natural killer (NK), IL2 stimulated NK, and lymphokineactivated killer cells by alcohol consumption. Cell. Immunol. 194, 205-212. doi: 10.1006/cimm.1999.1511

Steinbigler, P., Haberl, R., Konig, B., and Steinbeck, G. (2003). P-wave signal averaging identifies patients prone to alcohol-induced paroxysmal atrial fibrillation. Am. J. Cardiol. 91, 491-494. doi: 10.1016/S0002-9149(02)03258-7

Stephens, N. G., Parsons, A., Schofield, P. M., Kelly, F., Cheeseman, K., and Mitchinson, M. J. (1996). Randomised controlled trial of vitamin E in patients with coronary disease: Cambridge Heart Antioxidant Study (CHAOS). Lancet 347, 781-786. doi: 10.1016/S0140-6736(96)90866-1

Sterlacci, W., Saker, S., Huber, B., Fiegl, M., and Tzankov, A. (2016). Expression of the CXCR4 ligand SDF-1/CXCL12 is prognostically important for adenocarcinoma and large cell carcinoma of the lung. Virchows Arch. 468, 463-471. doi: 10.1007/s00428-015-1900-y

Swardfager, W., Lanctot, K., Rothenburg, L., Wong, A., Cappell, J., and Herrmann, N. (2010). A meta-analysis of cytokines in Alzheimer's disease. Biol. Psychiatry 68, 930-941. doi: 10.1016/j.biopsych.2010.06.012

Tarzami, S. T., Calderon, T. M., Deguzman, A., Lopez, L., Kitsis, R. N., and Berman, J. W. (2005). MCP-1/CCL2 protects cardiac myocytes from hypoxiainduced apoptosis by a G(alphai)-independent pathway. Biochem. Biophys. Res. Commun. 335, 1008-1016. doi: 10.1016/j.bbrc.2005.07.168

Tarzami, S. T., Cheng, R., Miao, W., Kitsis, R. N., and Berman, J. W. (2002). Chemokine expression in myocardial ischemia: MIP-2 dependent MCP-1 expression protects cardiomyocytes from cell death. J. Mol. Cell. Cardiol. 34, 209-221. doi: 10.1006/jmcc.2001.1503

Tarzami, S. T., Miao, W., Mani, K., Lopez, L., Factor, S. M., Berman, J. W., et al. (2003). Opposing effects mediated by the chemokine receptor CXCR2 on myocardial ischemia-reperfusion injury: recruitment of potentially damaging neutrophils and direct myocardial protection. Circulation 108, 2387-2392. doi: 10.1161/01.CIR.0000093192.72099.9A

Teos, L. Y., Zhao, A., Alvin, Z., Laurence, G. G., Li, C., and Haddad, G. E. (2008). Basal and IGF-I-dependent regulation of potassium channels by MAP kinases and PI3-kinase during eccentric cardiac hypertrophy. Am. J. Physiol. Heart Circ. Physiol. 295, H1834-H1845. doi: 10.1152/ajpheart.321.2008

Tobinick, E. (2006). Spinal delivery of p38: TNF-alpha inhibitors. PLoS Med. 3:e511. doi: 10.1371/journal.pmed.0030511
Tobinick, E., Gross, H., Weinberger, A., and Cohen, H. (2006). TNF-alpha modulation for treatment of Alzheimer's disease: a 6-month pilot study. MedGenMed 8, 25.

Torre-Amione, G., Kapadia, S., Lee, J., Durand, J. B., Bies, R. D., Young, J. B., et al. (1996). Tumor necrosis factor-alpha and tumor necrosis factor receptors in the failing human heart. Circulation 93, 704-711. doi: 10.1161/01.CIR.93.4.704

Torre-Amione, G., Stetson, S. J., Youker, K. A., Durand, J. B., Radovancevic, B., Delgado, R. M., et al. (1999). Decreased expression of tumor necrosis factoralpha in failing human myocardium after mechanical circulatory support: a potential mechanism for cardiac recovery. Circulation 100, 1189-1193. doi: 10.1161/01.CIR.100.11.1189

Umoh, N. A., Walker, R. K., Al-Rubaiee, M., Jeffress, M. A., and Haddad, G. E. (2014). Acute alcohol modulates cardiac function as PI3K/Akt regulates oxidative stress. Alcohol. Clin. Exp. Res. 38, 1847-1864. doi: 10.1111/acer.12459

Urbano-Marquez, A., and Fernandez-Sola, J. (2004). Effects of alcohol on skeletal and cardiac muscle. Muscle Nerve 30, 689-707. doi: 10.1002/mus.20168

Urbano-Marquez, A., and Fernandez-Sola, J. (2005). Alcohol consumption and heart failure. J. Card. Fail. 11, 329-332. doi: 10.1016/j.cardfail.2005.04.023

Vary, T. C., and Deiter, G. (2005). Long-term alcohol administration inhibits synthesis of both myofibrillar and sarcoplasmic proteins in heart. Metab. Clin. Exp. 54, 212-219. doi: 10.1016/j.metabol.2004.08.015

Vary, T. C., Lynch, C. J., and Lang, C. H. (2001). Effects of chronic alcohol consumption on regulation of myocardial protein synthesis. Am. J. Physiol. Heart Circ. Physiol. 281, H1242-H1251. doi: 10.1152/ajpheart.2001.281.3.H1242

Walker, R. K., Cousins, V. M., Umoh, N. A., Jeffress, M. A., Taghipour, D., Al-Rubaiee, M., et al. (2013). The good, the bad, and the ugly with alcohol use and abuse on the heart. Alcohol. Clin. Exp. Res. 37, 1253-1260. doi: 10.1111/acer.12109

Wan, X., Xia, W., Gendoo, Y., Chen, W., Sun, W., Sun, D., et al. (2014). Upregulation of stromal cell-derived factor 1 (SDF-1) is associated with macrophage infiltration in renal ischemia-reperfusion injury. PLoS ONE 9:e114564. doi: 10.1371/journal.pone.0114564

Wang, B., Wang, W., Niu, W., Liu, E., Liu, X., Wang, J., et al. (2014). SDF-1/CXCR4 axis promotes directional migration of colorectal cancer cells through upregulation of integrin $\alpha \mathrm{v} \beta 6$. Carcinogenesis 35, 282-291. doi: 10.1093/carcin/bgt331

Wang, K., Busker-Mannie, A. E., Hoeft, J., Vasquez, K., Miller, S. D., Melvold, R. W., et al. (2001). Prolonged Hya-disparate skin graft survival in ethanolconsuming mice: correlation with impaired delayed hypersensitivity. Alcohol. Clin. Exp. Res. 25, 1542-1548. doi: 10.1111/j.1530-0277.2001.tb02158.x

Wannamethee, G., and Shaper, A. G. (1992). Alcohol and sudden cardiac death. Br. Heart J. 68, 443-448. doi: 10.1136/hrt.68.11.443

Wannamethee, G., Shaper, A. G., Macfarlane, P. W., and Walker, M. (1995). Risk factors for sudden cardiac death in middle-aged British men. Circulation 91, 1749-1756. doi: 10.1161/01.CIR.91.6.1749

Wei, S. G., Zhang, Z. H., Yu, Y., and Felder, R. B. (2014). Central SDF1/CXCL12 expression and its cardiovascular and sympathetic effects: the role of angiotensin II, TNF-alpha, and MAP kinase signaling. Am. J. Physiol. Heart Circ. Physiol. 307, H1643-H1654. doi: 10.1152/ajpheart.00 432.2014

Wilkinson, D. A., and Carlen, P. L. (1980). Neuropsychological and neurological assessment of alcoholism; discrimination between groups of alcoholics. J. Stud. Alcohol 41, 129-139. doi: 10.15288/jsa.1980.41.129

Willeit, P., Zampetaki, A., Dudek, K., Kaudewitz, D., King, A., Kirkby, N. S., et al. (2013). Circulating microRNAs as novel biomarkers for platelet activation. Circ. Res. 112, 595-600. doi: 10.1161/CIRCRESAHA.111.300539

Wodak, A., and Richardson, P. J. (1982). Alcohol and the cardiovascular system. Br. J. Addict. 77, 251-258. doi: 10.1111/j.1360-0443.1982.tb02454.x

Wong, D., and Dorovini-Zis, K. (1996). Platelet/endothelial cell adhesion molecule-1 (PECAM-1) expression by human brain microvessel endothelial cells in primary culture. Brain Res. 731, 217-220. doi: 10.1016/0006-8993(96)00673-7

Xiao, F., Yuan, W., Li, X., Wang, G., Jiang, T., Wang, W., et al. (2014). A case of heart failure due to alcoholic cardiomyopathy combined with acute pulmonary embolism. J. Thorac. Dis. 6, E176-E180. doi: 10.3978/j.issn.2072-1439.2014.07.32 
Yang, B., Ye, D., and Wang, Y. (2013). Caspase-3 as a therapeutic target for heart failure. Expert Opin. Ther. Targets 17, 255-263. doi: $10.1517 / 14728222.2013 .745513$

Zeigler, D. W., Wang, C. C., Yoast, R. A., Dickinson, B. D., McCaffree, M. A., Robinowitz, C. B., et al. (2005). The neurocognitive effects of alcohol on adolescents and college students. Prev. Med. 40, 23-32. doi: 10.1016/j.ypmed.2004.04.044

Zgraggen, S., Huggenberger, R., Kerl, K., and Detmar, M. (2014). An important role of the SDF-1/CXCR4 axis in chronic skin inflammation. PLoS ONE 9:e93665. doi: 10.1371/journal.pone.0093665

Zhang, X., Klein, A. L., Alberle, N. S., Norby, F. L., Ren, B. H., Duan, J., et al. (2003). Cardiac-specific overexpression of catalase rescues ventricular myocytes from ethanol-induced cardiac contractile defect. J. Mol. Cell. Cardiol. 35, 645-652. doi: 10.1016/S0022-2828(03)00080-4

Zou, J., and Crews, F. (2006). CREB and NF- $\kappa B$ transcription factors regulate sensitivity to excitotoxic and oxidative stress induced neuronal cell death. Cell. Mol. Neurobiol. 26, 385-405. doi: 10.1007/s10571-006-9045-9
Zou, J., and Crews, F. (2010). Induction of innate immune gene expression cascades in brain slice cultures by ethanol: key role of NF-кB and proinflammatory cytokines. Alcohol. Clin. Exp. Res. 34, 777-789. doi: 10.1111/j.1530-0277.2010. 01150.x

Conflict of Interest Statement: The authors declare that the research was conducted in the absence of any commercial or financial relationships that could be construed as a potential conflict of interest.

Copyright (C) 2018 Obad, Peeran, Little, Haddad and Tarzami. This is an open-access article distributed under the terms of the Creative Commons Attribution License (CC $B Y)$. The use, distribution or reproduction in other forums is permitted, provided the original author(s) and the copyright owner are credited and that the original publication in this journal is cited, in accordance with accepted academic practice. No use, distribution or reproduction is permitted which does not comply with these terms. 